\title{
San'ani Arabic Stress in Harmonic Serialism
}

\author{
Faisal Al-Mohanna ${ }^{1}$ \\ ${ }^{1}$ King Saud University, Riyadh, Saudi Arabia \\ Correspondence: Faisal Al-Mohanna, King Saud University, Riyadh, Saudi Arabia. E-mail: \\ mohannaf@ksu.edu.sa
}

Received: September 3, $2021 \quad$ Accepted: October 4, $2021 \quad$ Online Published: October 23, 2021

doi:10.5539/ijel.v11n6p49 URL: https://doi.org/10.5539/ijel.v11n6p49

\begin{abstract}
The word stress system in San'ani Arabic exhibits patterns of stress placement that associate some level of prominence with syllables with long vowels and syllables that end in the left-leg of a geminate. The fact that such syllables always succeed in attracting stress away from other non-final CVC syllables, even beyond the final trisyllabic window, clearly indicates the role that underlying moraicity plays in the stress algorithm. The proposed account, offered in this paper for the word stress system in San'ani, is couched in Harmonic Serialism, as a serial version of Optimality Theory. Key to the analyses presented is the assumption of gradual prosodification. The distinction drawn between faithful and unfaithful prosodic operations allows for applying some in a parallel fashion, but confines others to serialism. Central to the analysis, as well, is the exceptional case of final stress, which is mainly attributed to the intrinsic prominence of syllables with underlying bimoraic sequences.
\end{abstract}

Keywords: Harmonic Serialism, harmonic improvement, gradualness, Optimality Theory, prosodification, syllabification, mora assignment, footing, stress assignment, two-layered moraic structure, local conjunction

\section{Introduction}

In quantity-sensitive stress systems, syllable weight plays a pivotal role in stress placement. Footing, as a metrical operation, is determined on the basis of the moraic content of individual syllables. Generally speaking, heavy syllables are usually considered prominent in their feet and eventually on the grid. San'ani Arabic, as a clear example of a quantity-sensitive stress system, is no exception to that. What distinguishes it from most quantity-sensitive systems, though, is the priority given to CVV and CVG syllables when compared with other CVC heavy syllables. An open syllable with a long vowel or a syllable with the left-leg of a geminate will always receive stress, no matter what other syllables there might be. This predominant characteristic of the stress system in San'ani is fundamental to the analysis developed in this paper.

The theoretical framework adopted in this paper is that of Harmonic Serialism. Being derivational in its nature, Harmonic Serialism is predicted to accommodate the different levels of prominence associated with CVV/CVG syllables on the one hand and CVC syllables on the other. To render that distinction feasible, the proposed account must assume successive, rather than parallel, prosodification. Operations such as syllabification, mora assignment, footing, and stress assignment will be arranged in consecutive derivational steps. Some of these operations, however, may be allowed to combine, depending on whether an operation is considered to be faithful or unfaithful at a given step. Another issue that is accounted for by assuming the prominence distinction between heavy syllables in San'ani is the occurrence of word-final stress. A local conjunction of two metrical constraints is utilised to optimise final stress assignment, a pattern that is systematically avoided in San'ani unless motivated by syllable prominence.

The paper is organised as follows. In Section 2, the word stress system in San'ani Arabic is presented in detail, giving enough examples of each pattern. Section 3 summarises the comprehensive rule-based analysis of San'ani word stress offered in Watson (2002). As indicated there, the main assumptions and arguments are adopted, and at times slightly adjusted to fit within the boundaries of the overall proposed account. Section 4 presents Harmonic Serialism and proceeds to the analysis of San'ani Arabic word stress patterns. Finally, Section 5 offers the concluding remarks.

\section{San'ani Word Stress}

San'ani Arabic (SA) is a variety of Arabic mainly spoken in the ancient city of San'a, the capital of today's 
Yemen, which is located in the south western region of the Arabian Peninsula. One of the most detailed accounts of SA word stress is presented in Watson (2002). Somewhat abridged and more focused versions are also included in Watson (2009 and 2011). This stress system is also discussed in Hulst and Hellmuth (2010), Davis (2011), Davis and Ragheb (2014), and Ryan (2019), all of whom refer to Watson (2002).

The word stress system in SA displays some characteristics, shared with many Arabic dialects. The most noticeable of these properties is the prominence given to final superheavy syllables and to non-final heavy syllables. Nonetheless, it might be argued that the attested word stress system in this particular dialect of Arabic is distinguished by its treatment of (non-final) CVV and CVG syllables (i.e., open syllables with long vowels and syllables that end with the left-leg of a geminate, respectively). In SA, these two syllable configurations are set apart, from the other ultimately possible heavy syllable CVC, by their ability to attract stress beyond the final trisyllabic window and also by their ability to attract stress away from a final superheavy syllable. The following algorithm and data, taken mainly from Watson (2002), summarise the word stress system in SA (Note 1).

(1) Stress Algorithm in San'ani

(i) Stress the rightmost non-final CVV or CVG syllable.
(a) ma.'kaa.tib
'offices'
(b) ?a.'saa.mii
'names'
(c) ba.'saa.tiin
'groves'
(d) 's $\mathrm{s}^{\mathrm{S}}$ aa.buun
'soap'
(e) 'xaa.ri.đziin
'going out pl. ms.'
(f) 'daa.ri.jaat
'knowing pl. fm.'
(g) mit.'?a $\cdot \chi$ i.raat
'late $p l . f m$.'
(h) ji.'hib.buu
'they $m s$. love/like'
(i) mu.'sadz. $\bar{d} 3$ i.la.tii 'my recorder'
(j) 'haa.ka.ð'a.haa
'like this'
(k) 'saa.fart
'I/you sg. ms. travelled'
(l) 'daw.wart
'I/you sg. ms. looked for'

(ii) Otherwise, stress a final CVVC/CVCC syllable.
(a) da.'rast
'I/you sg. ms. learnt'
(b) Rab.'sart
'I/you sg. ms. saw'
(c) gam.'bart
'I/you sg. ms. sat'
(d) laf.'laft
'I/you sg. ms. collected'
(e) mak.'tuub
'letter'
(f) ba.'naat
'girls'

(iii) Otherwise, stress the rightmost non-final CVC syllable up to the antepenultimate.
(a) 'laf.laf
'he collected'
(b) 'mak.laf
'woman'
(c) 'mad.ra.sih
'school'
(d) 'mak.la.fih
'his woman'
(e) $2 a b . ' s^{\mathrm{S}}$ ar.tih
'I/you sg. ms. saw him/it'

(iv) Otherwise, stress the leftmost CV syllable.
(a) 'ka.tab
'he wrote'
(b) 'da.ra.sat
'she learnt'
(c) 'ra.ga.ba.tih
'his neck' (Note 2)
(d) mak.'ta.ba.tii
'my library'

(v) Stress a final CVV in disyllabic adjectives or di- or trisyllabic verbs in the imperfect. 

(a) jif.9a.'luu
'they $m s$. do'
(b) t t a.'rii
'fresh'

With the exception of $(1 \mathrm{v})$ which is discussed in detail in Sections three and four, the four statements (1i, ii, iii, an -iv) gradually decrease in their priority specifications. As indicated above, the forms in (1i) show that a rightmost non-final CVV or CVG syllable will uniformly attract stress, no matter what other syllables there might be. Forms such as (1(i) $i$ and j) demonstrate the prominence associated with such syllables even when they occur outside the final trisyllabic stress window, a stress domain prevalently maintained in many other dialects of Arabic. Also, forms (1(i) c-g, k, and l) show how the priority given to CVV/CVG syllables even undermines final superheavy syllables. Only in the absence of these intrinsically prominent syllables, a final superheavy syllable CVVC or CVCC will succeed in attracting stress, as shown in (1ii), even when there are non-final heavy CVC syllables (1(ii) b-e). A non-final CVC syllable will be stressed only when there are no CVV, CVG, or superheavy syllables in the form, as exemplified in (1iii). A preantepenultimate CVC syllable, however, never attracts stress. This might be considered as the only case in the SA word stress system that is reminiscent of the final trisyllabic stress window. Later discussion will show how this pattern is accounted for. Forms in (1iv) represent the default stress pattern where the leftmost CV syllable is stressed when none of the more prominent alternatives is available (CVV/CVG, final CVVC/CVCC, or a penult/antepenult CVC). A form such as (1(iv) c), with preantepenultimate stress, clearly represents the possibility of the default stress to go beyond the final trisyllabic stress window. In addition, (1(iv) d) is an example of antepenultimate stress on a light CV syllable even when the preantepenult is a CVC.

The proposed account for SA word stress patterns, as presented in detail in Section four, assumes the notion of gradual prosodification, which is formalised in Harmonic Serialism. Harmonic Serialism, as developed in McCarthy $(2000,2002,2006)$, is a serial version of Optimality Theory, Prince and Smolensky $(1993,2004)$, with derivational evaluation steps. Fundamental to this Harmonic Serialism account of SA word stress is the assumption that underlying moraic structure distinguishes short vowels from long vowels and geminate consonants from non-geminate ones, as discussed in Hayes (1989). Underlyingly, a short vowel is linked to a single mora, but a long vowel is linked to two. Also, a geminate consonant is assigned one mora underlyingly, but a non-geminate one is not. Clearly, this notion of contrasting underlying moraic structure differentiates between CVV and CVG syllables and other syllable types, potentially enabling a gradual process of footing to assign them stress first.

Before going into the fine details of this proposed account, it is in order to review the comprehensive analysis offered in Watson (2002) of SA word stress. This will provide the ideal platform as most of the assumptions and arguments Watson presents are adopted in the proposed Harmonic Serialism account. The following section summarises Watson's analysis of SA word stress.

\section{A Rule-Based Analysis}

The metrical theory outlined in Hayes (1995) is adopted in Watson (2002) to analyse SA word stress. To account for the data, Watson assumes a left to right parsing of moraic trochees promoting the rightmost foot to bare primary stress. The account also presupposes final consonant extrametricality and final foot extrametricality. Watson (2002) lists the four main rules given in (2) below for word stress assignment in SA (Watson, 2002, p. 99):

(2) Word Stress Assignment Rules for SA

(a) Consonant Extrametricality $\mathrm{C} \rightarrow<\mathrm{C}>/$ _ $]_{\text {word }}$

(b) Foot Construction Form moraic trochees from left to right.

(c) Foot Extrametricality $\quad$ Foot $\rightarrow<$ Foot $>/ \ldots]_{\text {word }}$

(d) Word Layer Construction End Rule Right (ERR)

Watson (2002) applies these rules to forms where the rightmost non-final heavy syllable is the penult or antepenult and to forms with a final CVCC sequence. Clearly, the rules above will also account for the default word stress pattern whereby the leftmost light syllable is stressed. The four forms below demonstrate how the rules in (2) apply. The rule applications in (a), (b), and (c) are taken directly from Watson (2002): 
(3)
(a) $(\times)$ word layer construction

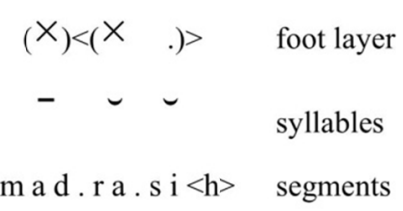

(b) ( $\times$ ) word layer construction

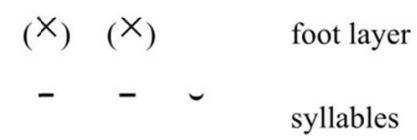

Pab.s $\mathrm{s}^{\mathrm{s}}$ ar.t $\mathrm{i}<\mathrm{h}>$ segments

(c) ( $\times$ ) word layer construction

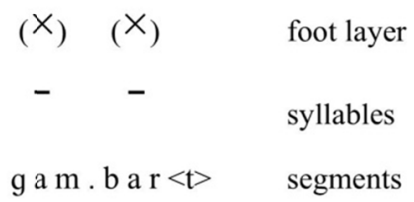

(d) (X ) word layer construction

$\left(\begin{array}{lll}X & .)<\left(\begin{array}{ll}X & .\end{array}\right)>\text { foot layer }\end{array}\right.$

$\checkmark \smile \smile \quad$ syllables

ra.g a.b a.t i $<\mathrm{h}>$ segments

Watson (2002) considers the final consonant in a final CVCC sequence as extrasyllabic. This justifies the different treatment of the rightmost foot in $(3 \mathrm{a}$ and $\mathrm{d})$ on the one hand and in $(3 \mathrm{c})$ on the other. In the latter case, the constraint against chaining extrametricality, as formalised in Hayes (1995), blocks the foot extrametricality rule. The rightmost foot is not considered peripheral because it may not include the final extrasyllabic consonant, which is not dominated by the preceding canonical CVC syllable but constitutes a degenerate syllable on its own. In (3 a and d), conversely, the final extrametrical consonant, which is part of the final syllable, is included in the rightmost peripheral foot that is also marked extrametrical.

Watson (2002) acknowledges the fact that the word stress assignment rules in (2) above are incapable of accounting for stress placement in forms with both a non-final CVV or CVG syllable and a final superheavy syllable. As shown in (1), a non-final CVV or CVG syllable is always stressed, even in forms in which the ultima is superheavy. In other words, a rightmost non-peripheral foot that is similar to the one in (3 c) will fail to attract stress when preceded anywhere in the word by a CVV or CVG syllable.

To address this issue, Watson (2002) calls on the notion of underlying moraic distinctness. Drawing on Hayes (1995), Watson assumes a two-layered moraic structure, where an underlyingly moraic segment is distinguished by having a mora on each layer, the lower layer and the upper layer. Weigh-by-Position (Hayes, 1989, 1995), on the other hand, renders a segment moraic on the lower layer only. Watson (2002) provides the diagrams below to demonstrate this moraic structural distinction (cf. Hayes, 1995): 
(4)

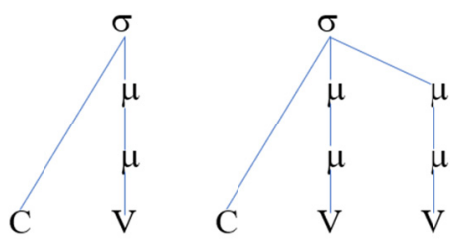<smiles>CC1CCCCC1CO</smiles>

From that, Watson (2002) assumes that footing in SA initially applies on the upper moraic layer unless there are no underlyingly bimoraic syllables in a given form, in which case feet are erected on the lower layer moras. Watson concludes that such an analysis justifies the lack of stress on a final CVCC superheavy syllable when preceded anywhere in the word by a CVV or CVG syllable. To show how that is the case, Watson (2002) provides the representations below, of the metrical structure for the forms /saafart/ and /dawwart/ with a non-final CVV and CVG syllables, respectively, comparing them to /gambart/ which has no underlyingly bimoraic syllables:

a. $(x$

(x)

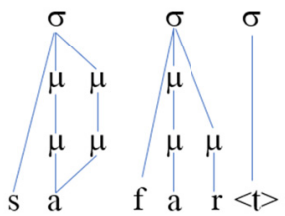

b. $(\mathrm{x})$

(x)

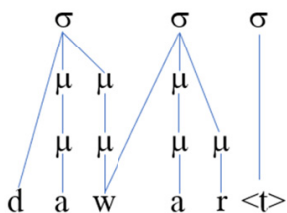

c. (

$\mathrm{x}$

)

(x)

(x)
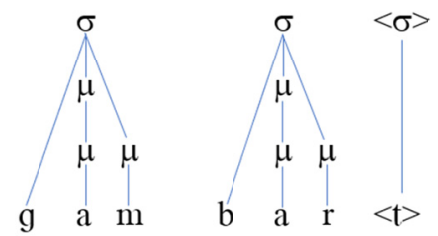

To account for the stress assignment in forms with a final CVVC sequence preceded anywhere in the word by a CVV or CVG syllable, Watson (2002) draws partly on works such as Selkirk (1981) and Broselow (1992), where final CVVC and CVCC sequences are assumed to be prosodically distinguished. Watson adopts the analysis where the structural distinction of a word-final CVVC sequence, when compared with a CVCC, lies in how the final consonant is treated. As mentioned above, the final consonant in a word-final CVCC is considered to be extrasyllabic and constitutes a degenerate syllable that is marked extrametrical, rendering the rightmost foot non-peripheral and blocking any rule of extrametricality from excluding that foot from stress assignment. On the other hand, a word-final CVVC is considered to be one bimoraic syllable, the final consonant of which is marked extrametrical. In such case, this final extrametrical consonant is dominated by the final syllable and ultimately by the final foot. Watson's account assumes that a foot erected on a word-final CVVC is peripheral and consequently subject to being marked extrametrical, explaining why stress is attracted to a preceding bimoraic CVV or CVG syllable. Utilising these assumptions, Watson (2002) analyses stress assignment in the forms $/ s^{\mathrm{S}}$ aabuun/ 'soap' and /dzazzaar/ 'butcher', as follows:

(6)

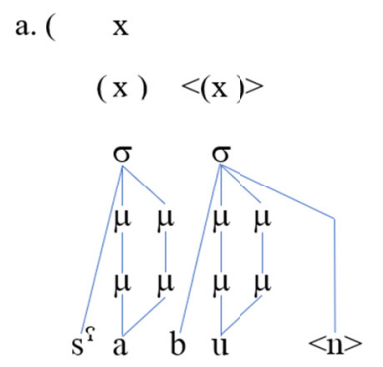

b. $(x$

(x) $<(\mathrm{x})>$

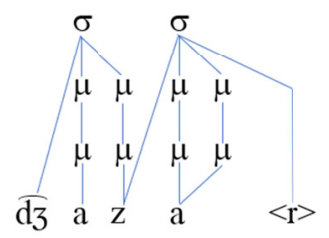


For words with a final CVVC syllable and no non-final CVV or CVG syllables as in /maktuub/ 'letter', where stress is assigned to the final CVVC syllable, Watson (2002) assumes that the Nonexhaustivity Condition, as formalised in Hayes $(1981,1995)$, blocks foot extrametricality. Again, Watson refers to the underlying moraic distinction, and claims that marking a foot erected on a final CVVC extrametrical, in a word such as /maktuub/, will deny any footing at the upper layer. In such forms, that final foot should remain visible, although peripheral; otherwise, the entire domain of the stress rules at the upper layer will be marked extrametrical. Consequently, the bimoraic syllable of this rightmost foot will attract stress.

Watson (2002) maintains the same rationale of the two-layered moraic structure and the Nonexhaustivity Condition to justify stress on a final CVV syllable that is preceded by a CV, CVC, or a sequence of CVC.CV syllables. In words such as [jik.tu.'buu] 'they $m s$. write' and [ $\mathrm{t}^{\mathrm{f}} \mathrm{a}$.'rii] 'fresh', Watson claims that a final foot built on the final CVV syllable is not marked extrametrical, as it provides the only moraic sequence that can be footed at the upper layer. Being the rightmost visible foot, it is most suited to attract stress. Watson compares these forms to the ones where a final CVV syllable is preceded by two CV syllables. In words such as [mak.'ta.ba.tii] 'my library' and ['ka.ta.buu]'they $m s$. wrote', marking the final foot extrametrical will not render the word footless at the upper layer. In other words, applying the foot extrametricality rule will not compromise the Nonexhaustivity Condition, as the preceding sequence of two CV syllables will constitute a foot at the upper layer. Watson (2002) presents the diagrams below to demonstrate the difference in footing and extrametricality between the two sets of CVV final words:

a. (

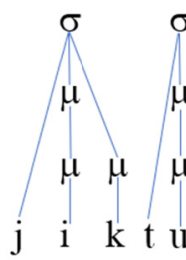

$\mathrm{x} \quad$ )

$(\mathrm{x})$

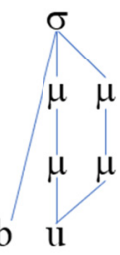

b. $(x$

$$
\left(\begin{array}{lll}
\mathrm{x} & \cdot)^{\prime} \quad<(\mathrm{x})>
\end{array}\right.
$$

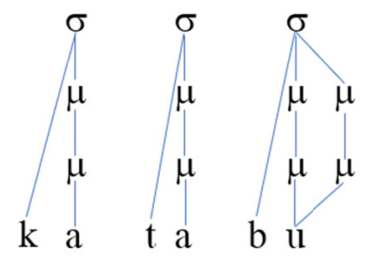

Watson (2002) concludes the main analysis of word stress patterns in SA with a note on words with preantepenultimate CVV or CVG syllables. As exemplified in (1i), the rightmost non-final CVV or CVG syllable will always attract stress, even when it is the preantepenult, as in [mu.'sadz. đzi.la.tii] 'my recorder' and ['haa.ka.ठ'a.haa] 'like this'. Watson notes that the proposed two-layered moraic structure is incapable of explaining this preantepenultimate stress. A word such as /haaka ${ }^{\Upsilon}$ ahaa/ will allow parsing three feet at the upper moraic level, the final of which could be marked extrametrical and the rightmost visible may wrongly receive stress *[(haa) ('ka. $\left.\delta^{\mathrm{S} a}\right)<($ haa $)>$ ]. To account for this discrepancy, Watson (2002) calls on Prominence Projection, as proposed in Hayes (1995). This should eventually rationalise the intrinsic prominence of CVV and CVG syllables when compared with CV syllables. Specifically, Watson suggests that prominence in SA should always be associated with the upper layer, projecting two prominence grid marks $(* *)$ for heavy syllables $(\mathrm{CVV} / \mathrm{CVG})$ and only one prominence grid mark $(*)$ for light syllables $(\mathrm{CV} / \mathrm{CVC})$. Finally, Watson asserts that ERR applies with reference to Prominence Projection, nominating for stress assignment the rightmost outrightly prominent syllable as in [('haa) $\left(k a . \partial^{\mathrm{S}} \mathrm{a}\right)<($ haa $)>$ ].

Although Watson (2002) presents a rather comprehensive and thorough analysis of SA word stress, the discussion runs into some complications and seemingly conflicting arguments. This should come as no surprise since SA, as described in Hulst and Hellmuth (2010), has a somewhat complex word stress system. An issue Watson (2002) acknowledges, in a footnote, and presents as a question for further research concerns the two-layered moraic structure and how footing should apply to render initial stress on words such as ['mak.ta.bih] 'library'. Collectively, the assumptions in the analysis summarised above will falsely assign stress to the penult, i.e., to the head of the peripheral foot which provides the only bimoraic sequence that may be footed at the upper moraic layer, *[mak ('ta.bih)]. Even when being considered peripheral, such foot will not be marked extrametrical because of the effects of the Nonexhaustivity Condition, a case similar to (7a). 
(8)

$\left.\begin{array}{ll}\left(\begin{array}{ll}\mathrm{x} & \end{array}\right) \\ (\mathrm{x} & .\end{array}\right)$

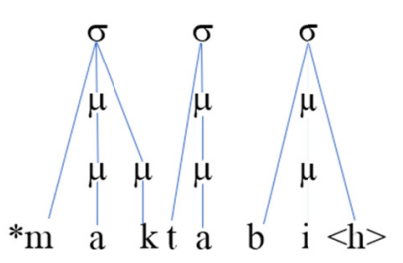

With this, the presentation of the rule-based analysis of SA word stress, given in Watson (2002), is concluded. A proposed analysis, of the same sets of data in (1), is pursued in the following section. The theoretical framework adopted is that of Harmonic Serialism, a derivational version of the constraint-based Optimality Theory.

\section{Harmonic Serialism for San'ani Word Stress}

The intrinsic prominence of non-final CVV and CVG syllables in SA ought to be treated distinctly. With their underlying moraic structure, these syllables are potentially available, from the outset, for footing into moraic trochees. This simple observation should determine how the analysis of SA word stress system must proceed. Parsing a CVV or a CVG syllable into a foot will create the docking site for stress assignment. This is arguably achieved prior to allowing Weight-by-Position to create other competing stress-attracting syllables. The advancement of Harmonic Serialism should accommodate for such gradual prosodification.

The detailed proposed account for the SA word stress system is presented and argued for in subsection 4.2. Before that, however, the following subsection (4.1) outlines the main principles of Harmonic Serialism and how they might be applied to footing and stress assignment.

\subsection{Harmonic Serialism}

Harmonic Serialism (HS), McCarthy (2000, 2002, 2006, 2010a, 2010b, 2016), is a serial version of the parallel Optimality Theory (P-OT), Prince and Smolensky (1993, 2004), McCarthy and Prince (1993a, 1993b). The fundamentally characteristic property that distinguishes HS is gradualness. In P-OT, multiple processes apply simultaneously allowing GEN to change an input in more than one way, and in one step. Consequently, what is submitted to EVAL in P-OT are sets of candidates potentially exhibiting considerable variation from their inputs (underlying representations) and from one another. In HS, this seemingly limitless variation in a candidate set is formally restricted and substantially reduced. Due to the property of gradualness, GEN in HS is only permitted to effect a maximum of one change that separates any given output candidate from its input. This curbed version of GEN and the facts known about the transformations, from underlying to surface representations, in natural languages will eventually express the other main property of HS, namely harmonic improvement.

With this limited range of operation GEN is allowed, HS could be interpreted at first sight as lacking the analytical power required in any theory of language analysis. Examples of alternation in which an underlying representation transforms in more than one way, to achieve the surface form, are attested in many natural languages. What is also true, about some of these changes an underlying representation undergoes, is that they are often derivational in nature, i.e., one leading to another. To accommodate such requirements, HS offers a series of derivational steps each of which incorporates a full pass through GEN and EVAL. As thoroughly explained in McCarthy (2016), these successive GEN-EVAL passes, which are referred to as steps, feed one another, in the sense that the output (most harmonic) candidate of a preceding step is the input to the immediately following one. As much as P-OT, harmony in HS is assessed in relation to the constraint hierarchy, which remains exactly the same throughout the various steps. To qualify for being the most harmonic in its immediate set of candidates, an output of any step is expected to demonstrate some harmonic improvement, if compared to its input. McCarthy states that this gradual harmonic improvement accumulates form one step to another until no further improvement is possible, in which case the derivational optimisation reaches an optimum that cannot be altered in any way to attain harmonic improvement. Then, and only then, the derivation converges, and the output of the final GEN-EVAL pass is nominated as the true output, the surface form. The basic architecture of HS could be summarised in the hypothetical example below, where EVAL is assumed to nominate the most harmonically improving candidate at each step: 
(9) HS's Architecture

Input: $/ \mathrm{X} / \rightarrow$ Output: [X11]

(i) Step $1\left(1^{\text {st }}\right.$ pass through GEN-EVAL $)$

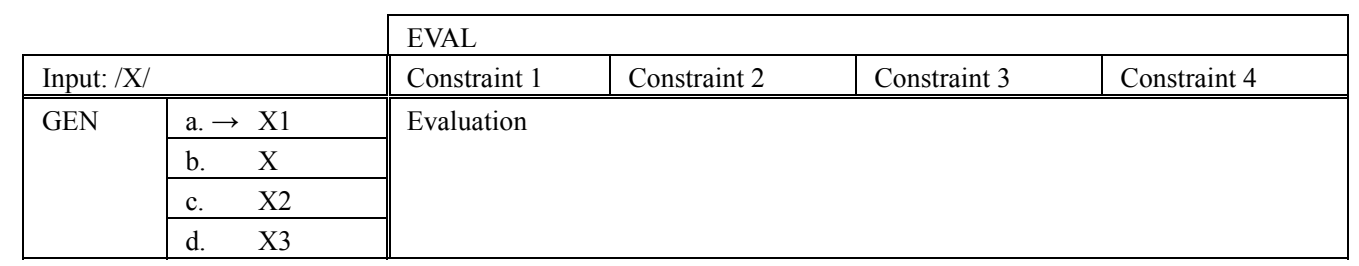

(ii) Step 2 ( $2^{\text {nd }}$ pass through GEN-EVAL)

\begin{tabular}{|c|c|c|c|c|c|}
\hline \multirow{2}{*}{\multicolumn{2}{|c|}{ Input: X1 }} & \multicolumn{4}{|l|}{ EVAL } \\
\hline & & Constraint 1 & Constraint 2 & Constraint 3 & Constraint 4 \\
\hline \multirow[t]{4}{*}{ GEN } & a. $\rightarrow$ X11 & \multirow[t]{4}{*}{ Evaluation } & & & \\
\hline & b. $\quad \mathrm{X} 1$ & & & & \\
\hline & c. X12 & & & & \\
\hline & d. $\quad \mathrm{X} 13$ & & & & \\
\hline
\end{tabular}

(iii) Step 3 ( $3^{\text {rd }}$ pass through GEN-EVAL) (Convergence)

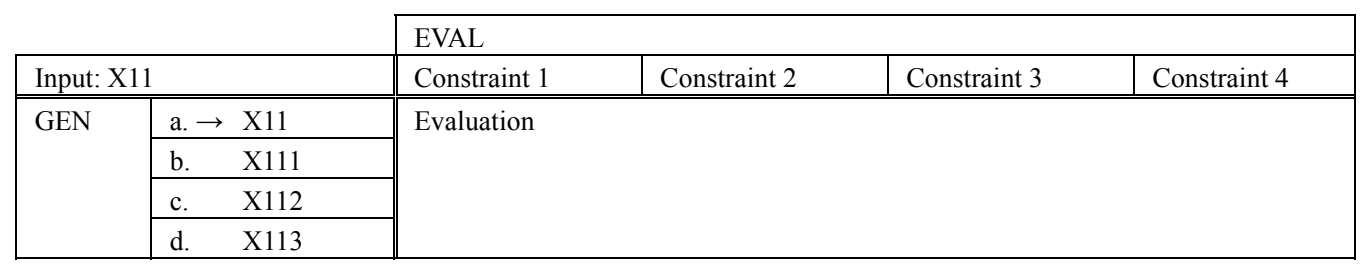

Footing/stress assignment within the framework of HS is discussed in much detail in Pruitt $(2008,2010$ and 2012). A proposed model, which is fully outlined in Pruitt (2012), treats footing as an iterative process. There, the sense of the term 'iterative' is slightly different form its usage in more traditional metrical theory. What Pruitt's model assumes is the series of optimizations in the HS's architecture, which would ultimately converge on a true output. Pruitt refers to this model of successive iterations as Iterative Foot Optimization (IFO). More specifically, such footing model aims for optimizing the most harmonic foot configuration which is attained gradually by erecting and promoting one 'best' foot at a time, Pruitt (2012).

Pruitt's footing model harbours two basic assumptions. The first assumption concerns foot binarity (syllabic binarity in particular) and foot headedness. By that, it is assumed that the set of candidates rendered by GEN, at any given step, is limited to those with a single instance of an added foot that is maximally disyllabic and essentially headed, i.e., with a flank assigned headedness. The other assumption entails what Pruitt (2010) refers to as 'strict inheritance'. Such principle guarantees that an erected foot in any preceding step is not modified in any way nor is it eliminated in any successive step. As a result, only unparsed syllables are considered for footing, in any given step.

In the following subsections, the substance of these principles and the basic formalism of HS are applied to the SA word stress system.

\subsection{Gradual Prosodification in SA}

The serial harmonic improvement, argued for in HS, is manifested in the SA word stress system through a multilayered operation of gradual prosodification. A number of prosodification processes apply serially, culminating in primary stress assignment. A central assumption of the proposed account draws on Pruitt (2012) where primary stress assignment is viewed as a process that applies freely whenever a single operation on an input allows it. Leading to that outcome, the prosodification processes involved are listed in (10): 
(10) Prosodification Processes

Syllabification

Mora assignment

Footing

Stress assignment

The sequence of applying these processes in SA is not always in accordance with that outlined in (10). As discussed in more detail later, the preferred sequence of applying such prosodification processes is slightly different from what the list above implies. Before going into the specifics of that, however, it will be helpful to highlight the main constraints assessing these processes.

Agreeing with several dialects of Arabic, SA allows coda consonants but prohibits complex syllable margins and onsetless syllables. In terms of the general syllable structure constraints presented in Prince and Smolensky $(1993,2004)$, such characteristics about syllable structure in SA are fundamentally specified in three basic constraints evaluating syllable margins.

(11) Syllable Structure Constraints (*COMPLEX, ONSET $>>$ NOCODA)

a. *COMPLEX

No more than one $\mathrm{C}$ may associate with any syllable margin.

b. ONSET

Syllables must have onsets.

c. NOCODA

Syllables must not have codas.

As for mora assignment, the proposed account assumes the morification model formalised in Hayes $(1989,1995)$. Underlyingly, short vowels are monomoraic, long vowels are bimoraic, and a sequence of a short vowel followed by the left-leg of a geminate is assigned two moras.

(12) Underlying Moraicity
(a) $\mu$
(b)

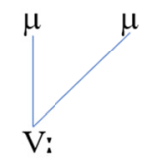
(b) $\left.\left.\right|_{\mathrm{V}} ^{\mu} \quad\right|_{\mathrm{G}} ^{\mu}$

This list of underlyingly moraic segments does not include the coda consonant in CVC syllables. To account for the fact that some languages treat these syllables as heavy, the rule/principle known as Weight-by-Position was introduced, Hayes (1989, 1995):

(13) Weight-by-Position

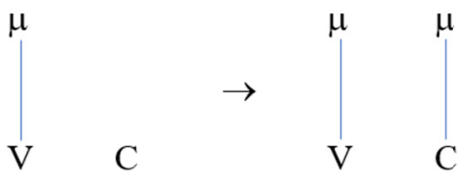

Weight-by-Position is also formalised as an OT constraint, Sherer (1994), Kager (1999) (Note 3):

(14) WEIGHT-BY-POSITION (WBYP)

Coda consonants are moraic.

Finally, the word stress assignment rules for SA, in (2) above, are interpreted into an initial set of metrical constraints. They assess foot type, word headedness, nonfinality, and quantity-sensitivity, Prince and Smolensky (1993, 2004), McCarthy and Prince (1993a). 
(15) Metrical Constraints

a. RHTYPE $=\mathrm{T}$

Rhythmic type is set at trochaic.

b. ALIGN-HEAD-R

Align (PrWd, R, H(PrWd), R)

c. Weight-to-Stress Principle (WSP)

Heavy syllables are prominent in foot structure and on the grid.

d. NON-FIN

No prosodic head is final in PrWd.

As the proposed account develops, subsequent discussion will demonstrate that the analysis of SA word stress system requires introducing further metrical constraints. Before considering such details in the following subsections, one issue requires clarification: which prosodification processes apply serially and which ones apply in parallel with other processes.

The application of a prosodification process is not necessarily equated with a change that requires a separate step in the serial harmonic improvement of an underlying string of segments. In McCarthy $(2006,2016)$, such operations that do not require steps on their own are characterised as faithful. An example of a faithful operation McCarthy refers to is syllabification (and resyllabification), which is contrasted with unfaithful operations such as syncope, epenthesis or feature change. McCarthy argues that because of the gradualness requirement on GEN, unfaithful operations may not be combined with one another in a single step; nonetheless, it is perfectly acceptable to combine an unfaithful operation with a faithful operation in a single derivational step.

Stress assignment might be considered as an example of unfaithful operations. The justification for such claim is grounded in the acoustic correlates of stress. Stress has always been associated with the relative prominence of a particular syllable in a word. This change affecting the stressed syllable is phonetically distinguished as an increase in duration, pitch, and loudness. Therefore, when compared to its prestressed input, a stressed syllable may not be considered as perfectly faithful. This argument concerning the unfaithful status of an operation that results in stress assignment is endorsed in McCarthy $(2010 \mathrm{~b}, 2016)$. On more than one occasion, McCarthy indicated that stress is assigned at a previous step before other operations (e.g., vowel shortening) may apply. Also, it is categorically specified, in McCarthy (2010b, p. 20), that stress (re)assignment may not be combined with an undisputedly unfaithful operation, such as denasalization, because of the gradualness requirement.

Alongside stress assignment, derivational mora assignment should be listed with the unfaithful operations. Altering the moraicity of an input by assigning a mora to an underlyingly nonmoraic coda consonant will ultimately be assessed as a violation of faithfulness. Such mora assignment will augment syllable weight and will potentially result in attracting stress. The constraint MORAFAITH is introduced in Broselow, Chen and Huffman (1997) to disfavour any mismatch between the moraicity in the input and the output. Rendering any underlyingly nonmoraic segment moraic on the surface will always instigate a violation of this faithfulness constraint. Consequently, derivational mora assignment may not be combined, at a given single step, with any other input altering operation such as stress assignment. However, a derivational step will always tolerate applying mora assignment and syllabification in parallel.

The question to address in relation to derivational mora assignment is whether such operation applies in parallel to all coda consonants in a form or iteratively, affecting one syllable at a time. Unlike footing, the assumption is that GEN, at a given step, will produce candidate sets with all coda consonants assigned moras rather than limiting the operation to a single syllable. As indicated above, Pruitt (2012) argues that typological evidence shows that primary stress assignment applies whenever possible, justifying the (IFO). However, there is no empirical evidence to convey the same rationale to mora assignment. It is acceptable for bounded stress systems, for example, to allow unparsed syllables, but no attested phenomena, in languages where coda consonants are considered to be moraic, select some syllable(s) in a given form for the application of Weight-by-Position leaving other syllables to surface with non-moraic coda consonants. Therefore, the proposed account for SA word stress system, which adopts gradual prosodification, will sanction single derivational steps where all coda consonants undergo parallel morification.

The classification in (16) summarises the discussion on faithful and unfaithful prosodic operations. Footing as a separate prosodic operation is not listed as faithful or unfaithful. The assumption adopted in the proposed account treats footing and stress assignment equally. Both will eventually nominate a particular flank of a foot 
for foot headedness and for prosodic word headedness at the same time. The argument for inseparability between constituents and their heads is clearly prevalent in the discussion on conflation in Halle and Vergnaud (1987). No constituent is preserved unless its head is represented on a higher line of the grid. The assumption, therefore, is fusing the two processes as one, Footing/Stress assignment (Note 4).

(16) Faithful and Unfaithful Operations

\section{Faithful}

Syllabification

\section{Unfaithful}

Derivational mora assignment

Stress assignment

With this discussion of faithful and unfaithful operations in mind, the path of gradual prosodification in SA may vary, according to the input being considered. Specifically, the most harmonic candidate designated by the constraint hierarchy in step 1 can be an output of the combined operations of syllabification and mora assignment or an output of the combined operations of syllabification and footing/stress assignment. In both cases, the faithful operation, syllabification, combines with either of the two unfaithful operations, mora assignment or footing/stress assignment. Obviously, the step where the derivation converges on the true output can only come after the step where stress is assigned.

(17) Options for Gradual Prosodification
(a) Step 1:
Syllabification $\rightarrow$ Mora assignment
Step 2:
Footing/Stress assignment
Step 3:
Convergence
(b) Step 1:
Syllabification $\rightarrow$ Footing/Stress assignment
Step 2:

\section{Convergence}

The analysis of SA word stress system, in the following subsections, will demonstrate how a particular input follows the gradual prosodification path of (17a) or (17b). What is decisive in that regard is the free operation of footing/stress assignment that will always apply and effect a change whenever an input string allows it (Note 5).

\subsubsection{Stress on Non-Final CVV and CVG Syllables}

The word stress system in SA gives priority to non-final CVV and CVG syllables. Such syllables are distinguished by their ability to attract stress beyond the final trisyllabic window and also by their ability to attract stress away from a final superheavy syllable, as exemplified in (1) above. What sets them apart from other syllable types in SA is the sequence of two underlying moras, assigned to a long vowel VV or a short vowel followed by the left-leg of a geminate VG. Potentially, this bimoraic sequence is parsed into a binary foot that is qualified to attract stress, assuming the free operation of footing and stress assignment that will apply whenever possible. In HS's terminology, an input with a non-final CVV or CVG sequence will elicit a prosodification path where footing/stress assignment combines with syllabification in step 1, delaying mora assignment till the following step. This, and the other derivational path, should ultimately result from the same constraint rankings.

Before attempting any metrical analysis of SA word stress, it is vital to assume that some constraints are undominated in the grammar of the language, throughout all derivational steps. One of these undominated constraints is FTBIN (Prince \& Smolensky, 1993, 2004), which requires that feet be binary under syllabic or moraic analysis. In addition to that, the metrical constraint RHTYPE=T (Prince \& Smolensky, 1993, 2004) is never violated in SA. It requires that feet are left-headed (trochaic). Also, the constraints HEADMAX and MONOHEADEDNESS (MONOHD) (Crowhurst, 1996) should be ranked undominated. Respectively, these two constraints require that a stressed syllable be dominated by the head of the prosodic word and that a prosodic word be uniquely headed. Assuming the inseparability argument (Halle \& Vergnaud, 1987), these two constraints are mutually demanding that each prosodic word contains a maximum of one foot (Note 6).

The first ranking argument to be discussed, which will be further tuned in the next subsection where the analysis is revised, is that regarding the constrains WSP and WBYP. In HS, each of these two constraints is pronouncing a prerogative that competes with the one made by the other. When GEN is only sanctioned to produce candidate sets with a maximum of one change away from the input, then it is either footing/stress assignment or mora assignment that will apply in order to satisfy WSP or WBYP, respectively, but certainly not both in any given step. In other words, each of these two unfaithful operations is evoked to satisfy one of the two constraints. Consequently, and for the time being, WSP will be ranked higher than WBYP to maintain the priority given to the intrinsically prominent CVV and CVG syllables, and to guarantee a prosodification path that applies 
footing/stress assignment whenever possible.

Other ranking arguments involve the constraint NON-FIN with regard to both WSP and ALIGN-HEAD-R. NON-FIN must dominate WSP to avoid stress on a final CVC syllable. Also, NON-FIN is ranked higher than ALIGN-HEAD-R to avoid pulling the head foot to the absolute right edge of the prosodic word. Although NON-FIN should be ranked relatively high in the constraint hierarchy, it may not be included in the set of undominated constraints. Later in subsection 4.2.5, when stress on final CVVC and CVV syllables is discussed, the exact ranking of NON-FIN will be finalised. For the time being, one more ranking argument should be considered. It concerns the constraints WSP and ALIGN-HEAD-R. As the priority given to quantity-sensitivity must out rank right edge preference for prosodic word headedness, WSP will be ranked higher than ALIGN-HEAD-R.

With this tentative ranking in mind, it is possible now to examine how gradual prosodification uniformly maintains stress on the rightmost non-final CVV or CVG syllable in the SA word stress system (Note 7). As indicated above, the choice in step 1 is between syllabification combined with mora assignment or syllabification combined with footing/stress assignment. In the proposed account, the latter is the preferred prosodification progression when a non-final CVV or CVG syllable occurs in the form. Analysing either ['dzaa.rat.naa] 'our neighbour fm.' or ['daw.war.naa] 'we looked for/he looked for us' will suffice to demonstrate how stress is assigned in such forms. Both include a sequence of two non-final underlying moras.

(18) HS analysis of stress on non-final CVV and CVG syllables (Note 8)

(i) Step 1 of /dzaaratnaa $\rightarrow$ ['] 3 aa.rat.naa] 'our neighbour $f m$.'

\begin{tabular}{|c|c|c|c|c|c|c|}
\hline 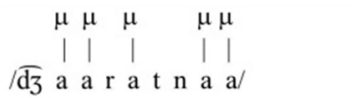 & $\begin{array}{l}\text { HEAD } \\
\text { MAX }\end{array}$ & $\begin{array}{c}\text { MONO } \\
\text { HD }\end{array}$ & $\begin{array}{c}\text { Non- } \\
\text { FIN }\end{array}$ & WSP & WBYP & $\begin{array}{c}\text { AligN- } \\
\text { HD-R }\end{array}$ \\
\hline 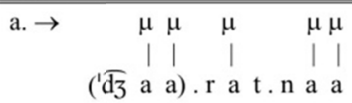 & & & & 1 & 1 & 2 \\
\hline 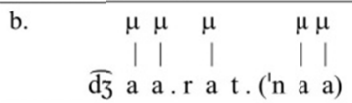 & & & $1 \mathrm{~W}$ & 1 & 1 & L \\
\hline 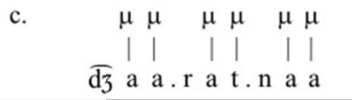 & & & & $3 \mathrm{~W}$ & L & L \\
\hline 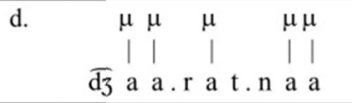 & & & & $2 \mathrm{~W}$ & 1 & L \\
\hline
\end{tabular}

(ii) Step 2 of /dzaaratnaa/ $\rightarrow$ ['d̄aa.rat.naa] 'our neighbour $f m$. .

\begin{tabular}{|c|c|c|c|c|c|c|}
\hline 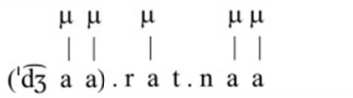 & $\begin{array}{l}\text { HEAD } \\
\text { MAXX }\end{array}$ & $\begin{array}{c}\text { MONo } \\
\text { HD }\end{array}$ & $\begin{array}{l}\text { Non- } \\
\text { FIN }\end{array}$ & WSP & WBYP & $\begin{array}{c}\text { ALIGN- } \\
\text { HD-R }\end{array}$ \\
\hline a. $\rightarrow \quad \begin{array}{ccccc}\mu & \mu & \mu & \mu & \mu \\
& \mid & \mid & \mid & \mid\end{array} \mid$ & & & & 1 & 1 & 2 \\
\hline 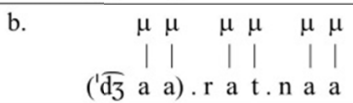 & & & & $2 \mathrm{~W}$ & L & 2 \\
\hline $\begin{array}{cccc}\mu \mu & \mu & \mu \mu \\
\mid & \mid & \mid & \mid \\
d_{3} \text { a a a.r a t.n } & \text { a a }\end{array}$ & & & & $2 \mathrm{~W}$ & 1 & L \\
\hline
\end{tabular}

In the first derivational step, two successive underlying moras are parsed into a single heavy syllable which is simultaneously footed and assigned stress. For that to be achieved, the proposed progression path in (17 b) had to win. Specifically, the priority given to bimoric syllables, which immediately surface as syllabification is applied, denies a rightmost non-final CVC syllable from attracting stress. This syllable has only on mora at this stage although it has the potential to become heavy if derivational mora assignment applies at a later step. Ranking WSP higher than WBYP renders this result. When candidates (18 i a) and (18 i c) are contrasted, this ranking argument is revealed. Satisfying WBYP at the expense of incurring more violations of the higher ranked WSP, as in $(18 \mathrm{i} \mathrm{c})$, is not the path for harmonic improvement in the SA grammar. On the other hand, assigning stress to a 
heavy syllable, and hence minimising violations of WSP, as in (18 i a), produces the most harmonic candidate that represents the true output in terms of stress placement. As for candidate $(18 \mathrm{i} \mathrm{b})$ that is favoured by ALIGN-HD-R and the fully faithful candidate (18 i d), the tableaux above show how violating NON-FIN or violating WSP more than once will make such candidates, respectively, less harmonic than (18 i a). Obviously, GEN does not produce any candidate that is two steps away from the input, i.e., one with both operations, mora assignment and footing/stress assignment, applying at the same time. In such candidate, a heavy CVC penult will be falsely considered as the best docking site for primary stress.

The derivation converges in step 2, where the input and the most harmonic candidate (18 ii a) are identical. The better prosodified candidate (18 ii b), where the coda consonant is rendered moraic, is not optimised by the current constraint ranking. Applying mora assignment creates an additional heavy syllable and consequently invokes an additional WSP violation. For the time being, this derivation will be accepted; however, such cases will be revisited in the following subsection, where stress on non-final CVC syllables is analysed. There, the proposed constraint ranking will be developed further.

A form with two non-final CVV syllables will show how the low-ranked ALIGN-HD-R emerges decisive, in step 1. The derivational steps in (19) demonstrate how the penult, rather than the antepenult, is stressed in a form such as [d] 3 ii.'raa.nih] 'his neighbours'. If assessed in comparison to (19 i b), the most harmonic candidate (19 i a) is a better satisfier of ALIGN-HD-R as only one syllable occurs between the left edge of the head foot and that of the prosodic word.

(19) HS analysis of stress on rightmost non-final CVV and CVG syllables

(i) Step 1 of /dziiraanih/ $\rightarrow$ [đ̄jii.'raa.nih] 'his neighbours'

\begin{tabular}{|c|c|c|c|c|c|c|}
\hline 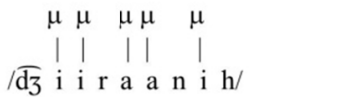 & $\begin{array}{l}\text { HEAD } \\
\text { MAX }\end{array}$ & $\begin{array}{c}\text { MONO } \\
\text { HD }\end{array}$ & $\begin{array}{c}\text { Non- } \\
\text { FIN }\end{array}$ & WSP & WBYP & $\begin{array}{c}\text { ALIGN- } \\
\text { HD-R }\end{array}$ \\
\hline 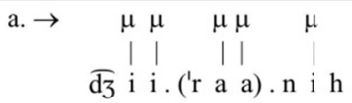 & & & & 1 & 1 & 1 \\
\hline 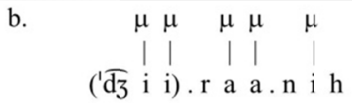 & & & & 1 & 1 & $2 \mathrm{~W}$ \\
\hline 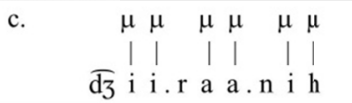 & & & & $3 \mathrm{~W}$ & $\mathrm{~L}$ & L \\
\hline 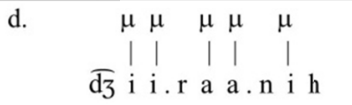 & & & & $2 \mathrm{~W}$ & 1 & $\mathrm{~L}$ \\
\hline
\end{tabular}

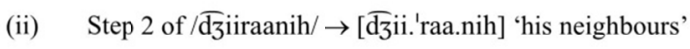

\begin{tabular}{|c|c|c|c|c|c|c|}
\hline 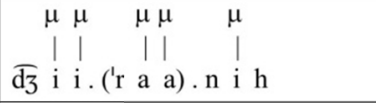 & $\begin{array}{l}\text { HEAD } \\
\text { MAX }\end{array}$ & $\begin{array}{c}\text { MONO } \\
\mathrm{HD}\end{array}$ & $\begin{array}{l}\text { NON- } \\
\text { FIN }\end{array}$ & WSP & WBYP & $\begin{array}{l}\text { ALIGN- } \\
\text { HD-R }\end{array}$ \\
\hline 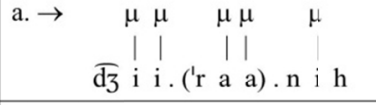 & & & & 1 & 1 & 1 \\
\hline 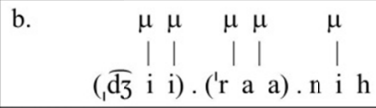 & $1 \mathrm{~W}$ & & & L & 1 & 1 \\
\hline 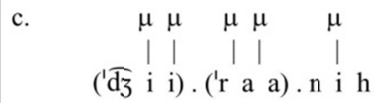 & & $1 \mathrm{~W}$ & & L & 1 & $3 \mathrm{~W}$ \\
\hline 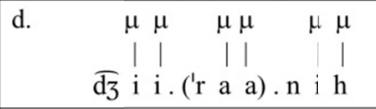 & & & & $2 \mathrm{~W}$ & L & 1 \\
\hline 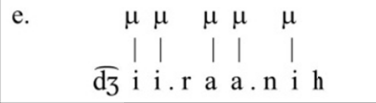 & & & & $2 \mathrm{~W}$ & 1 & L \\
\hline
\end{tabular}

The second derivational step in (19) reveals how active HEADMAX and MONOHD are. Jointly, these two constraints will only allow one foot per word. A candidate such as (19 ii b) is ruled out because it violates 
HEADMAX, as the head of the initial foot is not also the head of the prosodic word, and a candidate such as (19 ii c), which is not uniquely headed, fatally violates MONOHD. Such candidates are disfavoured even if they are better satisfiers of WSP.

The proposed account for word stress in SA continues in the following subsection where stress on non-final CVC syllables is analysed. There, it will be argued that the constraint ranking requires some adjustment, which should ultimately account for cases with non-final CVV or CVG syllables as well. Mainly, the constraint WSP is the focus of the discussion.

\subsubsection{Stress on Non-Final CVC Syllables}

As in the case of non-final CVV or CVG syllables, stress will eventually be placed on the rightmost non-final bimoraic CVC syllable. Nonetheless, the fact that a CVV or CVG syllable succeeds in attracting stress, even when it occurs to the left of a non-final CVC syllable (as in 17), indicates that footing/stress assignment combines with syllabification in step 1, where an underlying bimoraic sequence is parsed into a foot. On the other hand, it is mora assignment that combines with syllabification in step 1 in forms with no underlying bimoraic sequences, postponing footing/stress assignment until step 2, which is basically the prosodification path in (17 a). In this path, the most harmonic candidate in step 1 should be that which fully satisfies WBYP, as each coda consonant is assigned a mora. With regard to the constraint ranking assumed thus far, any such candidate will always be suboptimal, the reason being the higher ranking of WSP. Specifically, derivational mora assignment will create heavy syllables that may not be assigned stress at the same step, as mora assignment and stress assignment are two unfaithful operations that do not apply concurrently. The tableau in (20) shows how mora assignment is ruled out when WSP dominates WBYP.

\section{(20) WSP Militates against Mora Assignment}

Step 1 of /maktabkum/ $\rightarrow$ [mak.'tab.kum] 'your $p l$. ms. office'

\begin{tabular}{|c|c|c|c|c|c|c|}
\hline 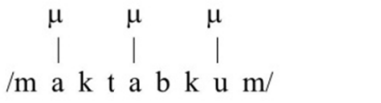 & $\begin{array}{l}\text { HEAD } \\
\text { MAX }\end{array}$ & $\begin{array}{c}\text { MONO } \\
\text { HD }\end{array}$ & $\begin{array}{l}\text { NON- } \\
\text { FIN }\end{array}$ & WSP & WBYP & $\begin{array}{c}\text { ALIGN- } \\
\text { HD-R }\end{array}$ \\
\hline 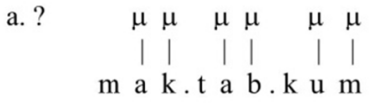 & & & & $3 \mathrm{~W}$ & L & \\
\hline 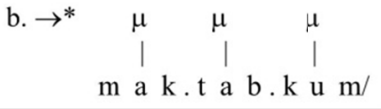 & & & & & 3 & \\
\hline
\end{tabular}

The intended winner in step 1 (20 a) fails to achieve any harmonic improvement when compared with its input; it is undoubtedly less harmonic than $(20 \mathrm{~b})$ because of the three WSP violations.

The proposed account of SA word stress system assumes a more specific, and consequently, higher ranked, variant of WSP. As formalised below, this constraint will assess the positive correlation between prominence and intrinsic quantity, in the sense of the two-layered moraic structure, explained above and diagrammed in (4).

(21) Weight-to-Stress Principle (Upper Layer Moras)

WSP-UP $\mu \mu$

Heavy syllables with upper layer moras are prominent in foot structure and on the grid.

A syllable containing an underlying bimoraic sequence that is not parsed into a foot will violate WSP-UP $\mu \mu$, but any candidate with no heavy syllables associated with two upper layer moras, will vacuously satisfy this constraint. For the SA word stress system, WBYP will be ranked between WSP-UP $\mu \mu$ and WSP (Note 9). The basic constraint ranking assumed thus far is given below.

(22) Basic Constraint Hierarchy for SA Word Stress System

FTBIN, RHTYPE $=T$, HEADMAX, MONOHEADEDNESS $>>$

NON-FIN $>>$ WSP-UP $\mu \mu>>$ WBYP $>>$ WSP $>>$ ALIGN-HD-R

The failed derivation in (20) is rerun in (23) with this ranking (Note 10). 
(23) HS analysis of stress on rightmost non-final CVC syllables

(i) Step 1 of /maktabkum/ $\rightarrow$ [mak.'tab.kum] 'your pl. ms. office'

\begin{tabular}{|c|c|c|c|c|c|}
\hline 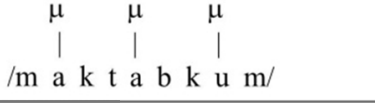 & NON-FIN & $\begin{array}{l}\text { WSP- } \\
\text { UP } \mu \mu\end{array}$ & WBYP & WSP & $\begin{array}{l}\text { ALIGN- } \\
\text { HD-R }\end{array}$ \\
\hline 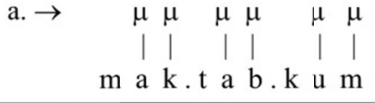 & & & & 3 & \\
\hline 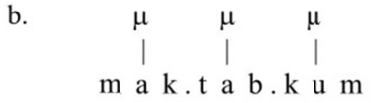 & & & $3 \mathrm{~W}$ & L & \\
\hline
\end{tabular}

(ii) Step 2 of /maktabkum/ $\rightarrow$ [mak.'tab.kum] 'your $p l$. ms. office'

\begin{tabular}{|c|c|c|c|c|c|}
\hline 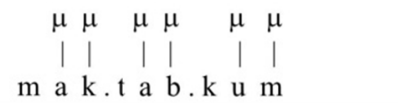 & NON-FIN & $\begin{array}{l}\text { WSP- } \\
\text { UP } \mu \mu\end{array}$ & WBYP & WSP & $\begin{array}{l}\text { AligN- } \\
\text { HD-R }\end{array}$ \\
\hline 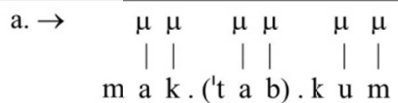 & & & & 2 & 1 \\
\hline 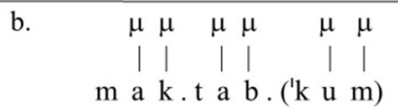 & $1 \mathrm{~W}$ & & & 2 & $\mathrm{~L}$ \\
\hline 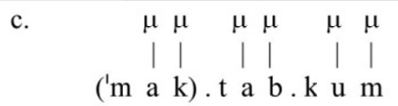 & & & & 2 & $2 \mathrm{~W}$ \\
\hline d. $\quad \begin{array}{rrrrr}\mu \mu & \mu & \mu & \mu & \mu \\
& \mid & \mid & \mid & \mid\end{array}$ & & & & $3 \mathrm{~W}$ & L \\
\hline
\end{tabular}

(iii) Step 3 of /maktabkum/ $\rightarrow$ [mak.'tab.kum] 'your pl. ms. office'

\begin{tabular}{|c|c|c|c|c|c|}
\hline 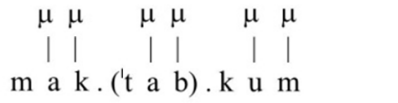 & Non-FIN & $\begin{array}{l}\text { WSP- } \\
\text { UP } \mu \mu\end{array}$ & WBYP & WSP & $\begin{array}{c}\text { AlIGN- } \\
\text { HD-R }\end{array}$ \\
\hline 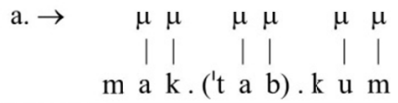 & & & & 2 & 1 \\
\hline b. $\quad \begin{array}{rrrr}\mu \mu & \mu \mu & \mu & \mu \\
& \mid & \mid & \mid\end{array}$ & & & & $3 \mathrm{~W}$ & $\mathrm{~L}$ \\
\hline
\end{tabular}

The first step in the derivation optimises complete morification. The winning candidate satisfies WBYP, which is thrice violated in the faithful form. Since footing and mora assignment are not allowed to apply in parallel at any given derivational step, no footed candidates are feasible in step 1. Any attempt to erect a foot on any of the three so far monomoraic syllables will inevitably violate FTBIN (Note 11). In the second step, the other unfaithful operation applies. Footing/stress assignment targets a different syllable in each of the first three candidates. NON-FIN and ALIGN-HD-R rule out the two competing suboptimal footing candidates, (23 ii b and c) respectively. On the other hand, the unfooted faithful candidate (23 ii d) is out of the contest all together, as it excessively violates WSP. In the third step, the derivation converges on the true output [mak.'tab.kum]. The winning candidates in all three steps are listed in the following harmonic improvement tableau, which demonstrates how harmony improves at each step of the derivation until convergence. 
(24) Harmonic Improvement Tableau for /maktabkum/ $\rightarrow$ [/mak.'tab.kum/]

\begin{tabular}{|c|c|c|c|c|c|c|}
\hline & $\begin{array}{l}\text { NON- } \\
\text { FIN }\end{array}$ & $\begin{array}{l}\text { WSP- } \\
\text { UP } \mu \mu\end{array}$ & WBYP & WSP & $\begin{array}{l}\text { ALIGN- } \\
\text { HD-R }\end{array}$ & \\
\hline 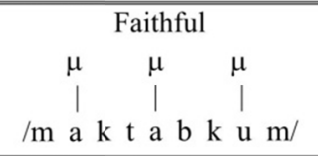 & & & 3 & & & \\
\hline 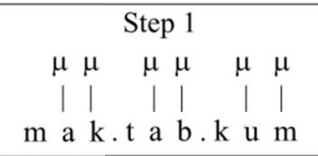 & & & & 3 & & \\
\hline 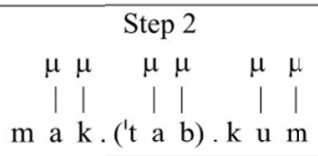 & & & & 2 & 1 & \\
\hline 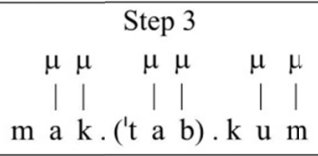 & & & & 2 & 1 & convergence \\
\hline
\end{tabular}

The stress algorithm in (1) draws a distinction between CVV and CVG syllables on the one hand and CVC syllables on the other. When weighed against those intrinsically prominent syllables, which can attract stress beyond the final trisyllabic window, a CVC syllable is only stressed if it occurs as the penult or antepenult. As justifying this behaviour will require a more extended analysis, it will be postponed to the subsection in which stress on CV syllables is analysed, where this and other related issues are discussed in more detail.

Another issue that merits consideration is the possibility of further prosodification after stress assignment. In particular, mora assignment could be allowed to apply after footing/stress assignment only to attain a more harmonic prosodification of an input. The relatively high ranking of WSP blocked that result in (18), and the derivation converged on a form depicting the true stress placement but containing non-moraic coda consonants. By ranking WBYP between WSP-UP $\mu \mu$ and WSP, a candidate with more harmonic prosodification is now achievable, as shown in the /dzaaratnaa/ $\rightarrow$ ['dzaa.rat.naa] derivation (Note 12). 
(25) Optimising Mora Assignment after Footing

(i) Step 1 of /dzaaratnaa/ $\rightarrow$ ['d̄aa.rat.naa] 'our neighbour $f m$.'

\begin{tabular}{|c|c|c|c|c|c|}
\hline 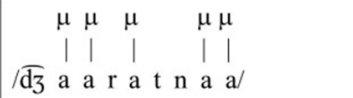 & $\begin{array}{c}\text { NoN- } \\
\text { FIN }\end{array}$ & $\begin{array}{l}\text { WSP- } \\
\text { UP } \mu \mu\end{array}$ & WвyP & WSP & $\begin{array}{c}\text { ALIGN- } \\
\text { HD-R }\end{array}$ \\
\hline 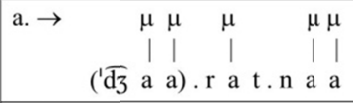 & & 1 & 1 & 1 & 2 \\
\hline $\begin{array}{cccc}\mu \mu & \mu & \mu \mu \\
\mid & \mid & \mid & \mid \\
\text { d3 a a } . r & \text { a t. } & \text { ('n } & \text { a a a })\end{array}$ & $1 \mathrm{~W}$ & 1 & 1 & 1 & L \\
\hline 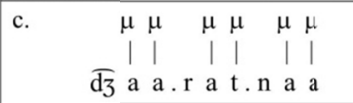 & & $2 \mathrm{~W}$ & L & 3 & L \\
\hline 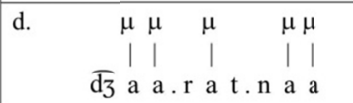 & & $2 \mathrm{~W}$ & 1 & 2 & L \\
\hline
\end{tabular}

(ii) Step 2 of /dzaaratnaa/ $\rightarrow$ ['d̄aa.rat.naa] 'our neighbour $f m$.'

\begin{tabular}{|c|c|c|c|c|c|}
\hline 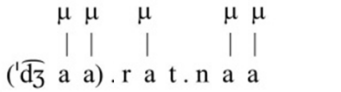 & $\begin{array}{c}\text { NoN- } \\
\text { FIN }\end{array}$ & $\begin{array}{l}\text { WSP- } \\
\text { UP } \mu \mu\end{array}$ & WBYP & WSP & $\begin{array}{l}\text { ALIGN- } \\
\text { HD-R }\end{array}$ \\
\hline 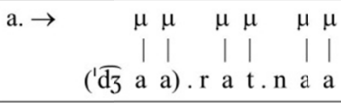 & & 1 & & 2 & 2 \\
\hline 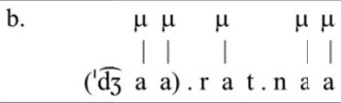 & & 1 & $1 \mathrm{~W}$ & 1 & 2 \\
\hline 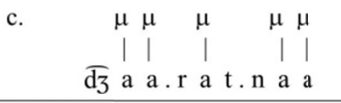 & & $2 \mathrm{~W}$ & 1 & 2 & L \\
\hline
\end{tabular}

(iii) Step 3 of /dzaaratnaa/ $\rightarrow$ ['d̄aa.rat.naa] 'our neighbour $f m$.'

\begin{tabular}{|c|c|c|c|c|c|}
\hline 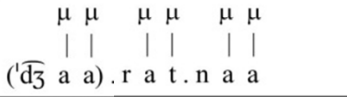 & $\begin{array}{c}\text { NON- } \\
\text { FIN }\end{array}$ & $\begin{array}{l}\text { WSP- } \\
\text { UP } \mu \mu\end{array}$ & WBYP & WSP & $\begin{array}{l}\text { ALIGN- } \\
\text { HD-R }\end{array}$ \\
\hline 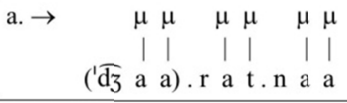 & & 1 & & 2 & 2 \\
\hline 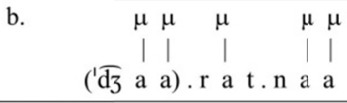 & & 1 & $1 \mathrm{~W}$ & 1 & 2 \\
\hline 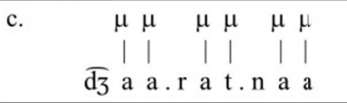 & & $2 \mathrm{~W}$ & & 2 & L \\
\hline
\end{tabular}

Although mora assignment will not in any way affect stress placement in such cases, it should be viewed as a step in the right direction in the sense of harmonic improvement. What is of more significance in that regard is that the constraint ranking WSP-UP $\mu \mu>$ WBYP $>>$ WSP does also achieve the desired effect in forms with non-final CVV/CVG, syllables such as /dzaaratnaa/ $\rightarrow$ ['] 3 aa.rat.naa]. The following subsection shows how that the same set of constraints and the same constraint ranking will suffice to account for stress on final CVCC syllables.

\subsubsection{Stress on Final CVCC Syllables}

As in many other dialects of Arabic, syllabification in SA observes a principle of maximal syllabic moraicity, by which syllables are maximally bimoraic. This applies to all syllable types, including superheavy syllables. Several examples are documented in the literature where such requirement regarding moraic maximality is formalised as a markedness constraint: BIMORA (Bakovic, 1996), SYLLBIN (Broselow, Chen, \& Huffman, 1997), SYL-MAXIMALITY $(\mu \mu)$ (Al-Mohanna, 2010), etc. The assumption for SA, as well as for many other dialects of Arabic, is to rank any one of these constraints undominated. An obvious consequence of that ranking is the nonmoraic status of the final consonant in superheavy syllables. Following Watson (2002), the proposed 
analysis of SA word stress system adopts two slightly different accounts explaining the final consonant nonmoraicity in CVCC syllables (detailed in this subsection) when compared with CVVC syllables (detailed in the subsection about stress on final CVVC syllables).

To avoid violating WBYP and at the same time satisfy an undominated constraint that limits the moraic content of a syllable to maximally two moras, the final consonant of a final CVCC sequence may be considered as being extrasyllabic, constituting a degenerate syllable on its own. This view of a final degenerate syllable is presented in Aoun (1979), adopted in Selkirk (1981), and slightly modified in McCarthy and Prince (1990).

(26) Final Degenerate Syllable (Extrasyllabic Consonant)

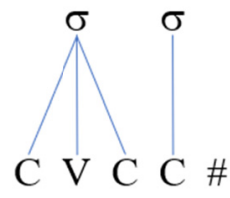

As indicated by Watson (2002), this syllabic configuration means that a final CVCC sequence, which is conventionally characterised as a superheavy syllable, is basically a concatenation of a CVC syllable and a degenerate syllable. For the word stress system in SA, this ultimately means that a (degenerate) syllable occurs between a CVC syllable and the right edge of the prosodic word. In other words, a CVCC sequence is interpreted by the SA grammar as a degenerate syllable preceded by a non-final CVC syllable that may be assigned stress without violating NON-FIN, as much as any other non-final CVC syllable.

(27) HS analysis of stress on final CVCC syllables

(i) Step 1 of/gambart/ $\rightarrow$ [gam.'bart] 'I/you sg. ms. sat'

\begin{tabular}{|c|c|c|c|c|c|}
\hline $\begin{array}{c}\mu \\
\mid \mathrm{g} \\
\mid\end{array}$ & NON-FIN & $\begin{array}{l}\text { WSP- } \\
\text { UP } \mu \mu\end{array}$ & WBYP & WSP & $\begin{array}{c}\text { ALIGN- } \\
\text { HD-R }\end{array}$ \\
\hline 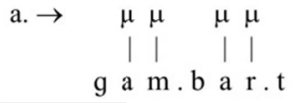 & & & & 2 & \\
\hline 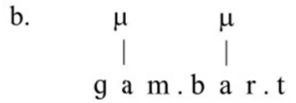 & & & $2 \mathrm{~W}$ & L & \\
\hline
\end{tabular}

(ii) Step 2 of /gambart/ $\rightarrow$ [gam.'bart] 'I/you sg. ms. sat'

\begin{tabular}{|c|c|c|c|c|c|}
\hline 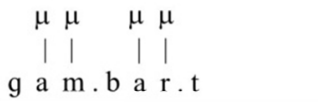 & NON-FIN & $\begin{array}{l}\text { WSP- } \\
\text { UP } \mu \mu\end{array}$ & WBYP & WSP & $\begin{array}{c}\text { Align- } \\
\text { HD-R }\end{array}$ \\
\hline 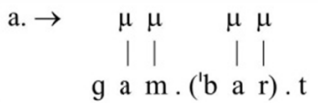 & & & & 1 & 1 \\
\hline 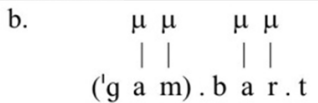 & & & & 1 & $2 \mathrm{~W}$ \\
\hline 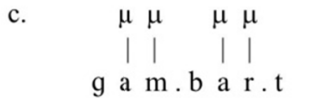 & & & & $2 \mathrm{~W}$ & $\mathrm{~L}$ \\
\hline
\end{tabular}

(iii) Step 3 of /gambart/ $\rightarrow$ [gam.'bart] 'I/you sg. ms. sat'

\begin{tabular}{|c|c|c|c|c|c|}
\hline 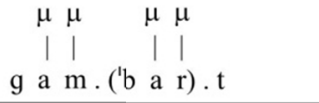 & NON-FIN & $\begin{array}{l}\text { WSP- } \\
\text { UP } \mu \mu\end{array}$ & WBYP & WSP & $\begin{array}{l}\text { ALIGN- } \\
\text { HD-R }\end{array}$ \\
\hline 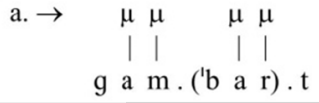 & & & & 1 & 1 \\
\hline 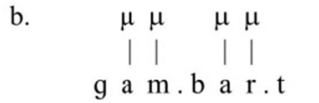 & & & & $2 \mathrm{~W}$ & L \\
\hline
\end{tabular}


The derivation in (27) shows that mora assignment is optimised in step 1, and footing/stress assignment selects the rightmost non-final heavy syllable in step 2, on which the derivation converges in step 3 . This prosodification path makes it logical to assume that a final CVCC is incapable of attracting stress away form a non-final CVV or CVG syllable, that takes the shorter path to stress assignment: [('saa).fart] and [('daw).wart] not *[saa.('far).t] or *[daw.('war).t].

(28) Final CVCC Losing to Non-final CVV/CVG

(i) Step 1 of /dawwart/ $\rightarrow$ ['daw.wart] 'I/you sg. ms. looked for'

\begin{tabular}{|c|c|c|c|c|c|}
\hline 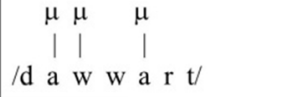 & $\begin{array}{c}\text { Non- } \\
\text { FIN }\end{array}$ & $\begin{array}{l}\text { WSP- } \\
\text { Up } \mu \mu\end{array}$ & WEYP & WSP & $\begin{array}{l}\text { ALIGN- } \\
\text { HD-R }\end{array}$ \\
\hline a. $\rightarrow \quad \begin{array}{ccc}\mu & \mu & \mu \\
& \mid & \mid \\
& \text { ('d a w) } & \text { w a r.t }\end{array}$ & & & 1 & & 2 \\
\hline 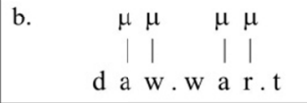 & & $1 \mathrm{~W}$ & L & $2 \mathrm{~W}$ & L \\
\hline $\begin{array}{ccc}\text { c. } \quad \mu \mu & \mu \\
& \text { d a w.w } & \text { a r.t }\end{array}$ & & $1 \mathrm{~W}$ & 1 & $1 \mathrm{~W}$ & L \\
\hline
\end{tabular}

(ii) Step 2 of /dawwart/ $\rightarrow$ ['daw.wart] 'I/you $s g$. $m s$. looked for'

\begin{tabular}{|c|c|c|c|c|c|}
\hline $\begin{array}{ccc}\mu \mu & \mu \\
\mid & \mid \\
\text { ('d a w). w } & \text { a r.t }\end{array}$ & $\begin{array}{c}\text { NoN- } \\
\text { FIN }\end{array}$ & $\begin{array}{l}\text { WSP- } \\
\text { UР } \mu \mu\end{array}$ & WeYP & WSP & $\begin{array}{c}\text { ALIGN- } \\
\text { HD-R }\end{array}$ \\
\hline 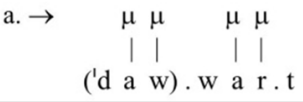 & & & & 1 & 2 \\
\hline 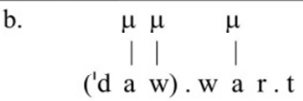 & & & $1 \mathrm{~W}$ & $\mathrm{~L}$ & 2 \\
\hline $\begin{array}{c}\text { c. } \quad \begin{array}{l}\mu \mu \\
\mid \\
\text { d a w.w }\end{array} \text { a r.t }\end{array}$ & & $1 \mathrm{~W}$ & $1 \mathrm{~W}$ & 1 & $\mathrm{~L}$ \\
\hline
\end{tabular}

(iii) Step 3 of /dawwart/ $\rightarrow$ ['daw.wart] 'I/you $s g$. ms. looked for'

\begin{tabular}{|c|c|c|c|c|c|}
\hline 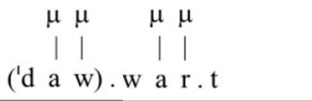 & $\begin{array}{c}\text { NoN- } \\
\text { FIN }\end{array}$ & $\begin{array}{l}\text { WSP- } \\
\text { UP } \mu \mu\end{array}$ & WEYP & WSP & $\begin{array}{c}\text { ALIGN- } \\
\text { HD-R }\end{array}$ \\
\hline 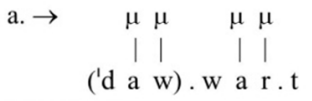 & & & & 1 & 2 \\
\hline 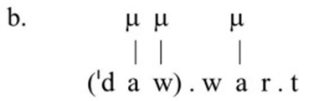 & & & $1 \mathrm{~W}$ & $\mathrm{~L}$ & 1 \\
\hline
\end{tabular}

In the next subsection, the proposed account proceeds to analysing the pattern where stress is assigned to a light CV syllable.

\subsubsection{Stress on CV Syllables}

Thus far, it has been demonstrated that footing applies at the instigation of WSP-UP $\mu \mu$ and WSP. With forms in which all (non-final) syllables are light, nonetheless, it may not be argued that these two constraints are responsible in any way for motivating footing, and eventually stress assignment. A different constraint is required, one that is independently motivated by exhaustivity in prosodic domains, namely PARSE- $\sigma$ (Prince \& Smolensky, 1993, 2004).

(29) Parsing (Light) Syllables

PARSE- $\sigma$

Syllables are parsed by feet. 
For SA, the constraint PARSE- $\sigma$ must be ranked lower than WBYP to allow mora assignment to apply even when that would leave a sequence of syllables unparsed. This ranking will allow the grammar to create stress attracting heavy syllables before parsing light syllables into binary feet, which is the logical path of prosodification especially in step 1. Conversely, PARSE- $\sigma$ must be ranked higher than ALIGN-HD-R to avoid nominating any footless candidate that vacuously satisfies ALIGN-HD-R from being optimised. A basic analysis of forms with no non-final heavy syllables, ones where stress is places on the leftmost light syllable, should reveal how the constraint PARSE- $\sigma$ is active in promoting true outputs.

(30) HS analysis of stress on leftmost CV syllables (Basic analysis)

(i) Step 1 of /darasat/ $\rightarrow$ ['da.ra.sat] 'she learnt'

\begin{tabular}{|c|c|c|c|c|c|c|}
\hline 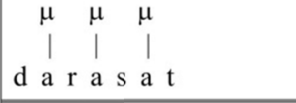 & $\begin{array}{c}\text { Non- } \\
\text { FIN }\end{array}$ & 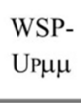 & WBYP & WSP & $\begin{array}{c}\text { PARSE- } \\
\sigma\end{array}$ & $\begin{array}{l}\text { ALIGN- } \\
\text { HD-R }\end{array}$ \\
\hline 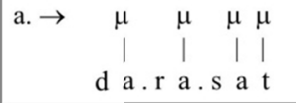 & & & & 1 & 3 & \\
\hline 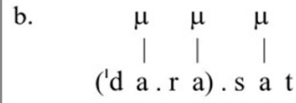 & & & $1 \mathrm{~W}$ & L & $1 \mathrm{~L}$ & $1 \mathrm{~W}$ \\
\hline 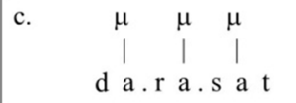 & & & $1 \mathrm{~W}$ & L & 3 & \\
\hline
\end{tabular}

(ii) Step 2 of /darasat/ $\rightarrow$ ['da.ra.sat] 'she learnt'

\begin{tabular}{|c|c|c|c|c|c|c|}
\hline 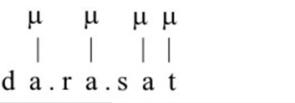 & $\begin{array}{l}\text { Non- } \\
\text { FIN }\end{array}$ & $\begin{array}{l}\text { WSP- } \\
\text { UP } \mu \mu\end{array}$ & WBYP & WSP & $\begin{array}{c}\text { PARSE- } \\
\sigma\end{array}$ & $\begin{array}{c}\text { ALIGN- } \\
\text { HD-R }\end{array}$ \\
\hline 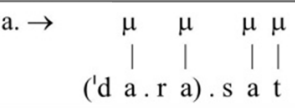 & & & & 1 & 1 & 1 \\
\hline $\begin{array}{llll}\text { b. } & \mu & \mu & \mu \mu \\
\mid & \mid & || \\
\text { d a.r a } & \text { ('s a t) }\end{array}$ & $1 \mathrm{~W}$ & & & $\mathrm{~L}$ & $2 \mathrm{~W}$ & $\mathrm{~L}$ \\
\hline 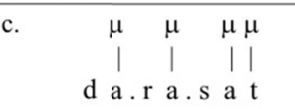 & & & & 1 & $3 \mathrm{~W}$ & $\mathrm{~L}$ \\
\hline
\end{tabular}

(iii) Step 3 of /darasat/ $\rightarrow$ ['da.ra.sat] 'she learnt'

\begin{tabular}{|c|c|c|c|c|c|c|}
\hline 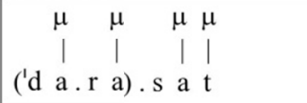 & $\begin{array}{l}\text { Non- } \\
\text { FIN }\end{array}$ & 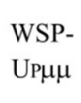 & WBYP & WSP & $\begin{array}{c}\text { PARSE- } \\
\sigma\end{array}$ & $\begin{array}{l}\text { ALIGN- } \\
\text { HD-R }\end{array}$ \\
\hline 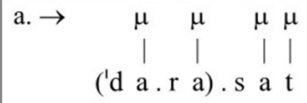 & & & & 1 & 1 & 1 \\
\hline 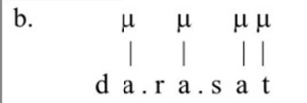 & & & & 1 & $3 \mathrm{~W}$ & L \\
\hline
\end{tabular}

In step 2, where the main action happens, footing/stress assignment wins in (30 ii a) despite causing a violation of ALIGN-HD-R. This intended result is achieved only because the winning candidate is a better satisfier of PARSE- $\sigma$, when compared with the competing totally unparsed suboptimal candidate (30 ii c).

It must be noted that the proposed account assumes ranking PARSE- $\mu$ (Prince \& Smolensky, 1993, 2004) between PARSE- $\sigma$ and ALIGN-HD-R. Violating PARSE- $\mu$, by not parsing the final mora, and the final consonant to which it is assigned, into the final syllable (linking it directly to the PrWd node), will allow footing/stress assignment to apply in disyllabic words such as $[(\text { 'ka.ta })]_{\mathrm{PrWd}}$ 'he wrote' without violating NON-FIN. This violation of PARSE- $\mu$ is sacrificed to avoid violating the higher ranked constraint PARSE- $\sigma$. In trisyllabic words, no such violation is required to render more syllables parsed and to satisfy NON-FIN at the same time. The only benefit of violating PARSE- $\mu$ in trisyllabic words is to achieve a better satisfaction of the lower ranked ALIGN-HD-R (Note 13). To render the true outputs more harmonic, in both disyllabic and 
trisyllabic words, however, it is vital to include in the hierarchy the constraint $* \operatorname{NONCD}\left(\mathrm{C}_{\mu}\right)$ which disfavours candidates with moraic consonants that are not assigned to a coda position, ranking it higher than PARSE- $\sigma$ and alongside WSP. The following two tableaux, which join the derivation in step 2, show how the interaction between PARSE- $\sigma$ and PARSE- $\mu$ forces final segment underparsing only in disyllabic words, but never in trisyllabic (and consequently any larger) words.

(31) PARSE- $\sigma$ Motivating PARSE- $\mu$ Violation in Disyllabic Words

(i) Step 2 of $/ \mathrm{katab} / \rightarrow$ ['ka.tab] 'he wrote'

\begin{tabular}{|c|c|c|c|c|c|c|c|c|}
\hline $\begin{array}{cccc}\mu & \mu & \mu \\
& \mid & \mid & \mid \\
k & a \cdot t & a & b\end{array}$ & $\begin{array}{l}\frac{z}{3} \\
\frac{1}{z} \\
\frac{1}{2} \\
z\end{array}$ & 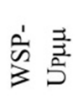 & $\begin{array}{l}\text { 髉 } \\
\text { ३े }\end{array}$ & $\vec{n}$ & 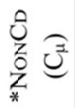 & 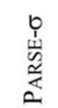 & 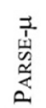 & 党䚄 \\
\hline 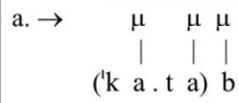 & & & & & 1 & & 1 & \\
\hline 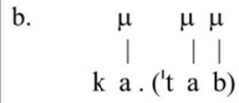 & $1 \mathrm{~W}$ & & & & L & $1 \mathrm{~W}$ & $\mathrm{~L}$ & \\
\hline $\begin{array}{llll}\text { c. } & & \mu & \mu \\
& & \mid & \mid \\
& k & a & \\
& & \text { t } & \text { a b }\end{array}$ & & & $1 \mathrm{~W}$ & & L & $2 \mathrm{~W}$ & & \\
\hline $\begin{array}{lllll}\text { d. } & \mu & \mu & \mu \\
& & \mid & \mid & \mid \\
& k & \text { a.t } & \text { a } & \text { b }\end{array}$ & & & & $1 \mathrm{~W}$ & L & $2 \mathrm{~W}$ & $\mathrm{~L}$ & \\
\hline
\end{tabular}

(ii) Step 2 of /darasat/ $\rightarrow$ ['da.ra.sat] 'she learnt'

\begin{tabular}{|c|c|c|c|c|c|c|c|c|}
\hline $\begin{array}{cccc}\mu & \mu & \mu \mu \\
\mid & \mid & \mid & \mid \\
\text { d } & \text { a.r } & \text { a.s } & \text { a t t }\end{array}$ & 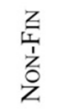 & 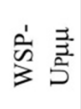 & $\begin{array}{l}\text { 商 } \\
\text { 吾 }\end{array}$ & ${ }_{i}^{\tilde{w}}$ & 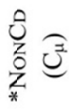 & 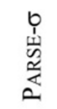 & 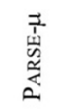 & 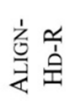 \\
\hline 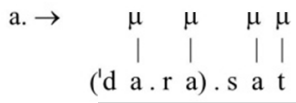 & & & & 1 & & 1 & & 1 \\
\hline 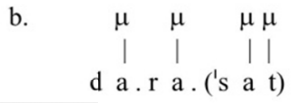 & $1 \mathrm{~W}$ & & & L & & $2 \mathrm{~W}$ & & $\mathrm{~L}$ \\
\hline 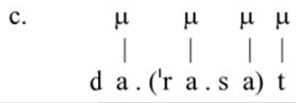 & & & & L & W & 1 & $1 \mathrm{~W}$ & L \\
\hline 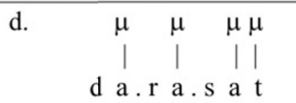 & & & & 1 & & $3 \mathrm{~W}$ & & L \\
\hline
\end{tabular}

In (31 i), all possible competing candidates are violators of PARSE- $\sigma$. In the winning candidate, parsing both syllables into an even trochee is rendered possible because the final mora/consonant is excluded from the second syllable, which clearly causes a violation of the lower ranked PARSE- $\mu$ (Note 14). In contrast, the suboptimal candidate in (31 ii c) needlessly violates PARSE- $\mu$ to achieve no benefit, in terms of syllable parsing. Although this losing candidate satisfies WSP, it violates ${ }^{*} \operatorname{NONCD}\left(\mathrm{C}_{\mu}\right)$. This does not make it more harmonic than the winner which has the opposite assessment of these two constraints that are not relatively ranked. Apparently, the winner in $(31$ i) undergoes two operations: resyllabification, by unparsing the final mora/consonant, and footing/stress assignment. These two operations are allowed to apply simultaneously as resyllabification is considered to be one of the faithful operations that may combine with any unfaithful operation, such as footing/stress assignment.

It is now appropriate to return to the question of why stress systematically avoids a preantepenultimate CVC syllable, docking in instead on the leftmost light syllable (the antepenult). In SA, a non-final CVC syllable is only stressed if it occurs as the penult or antepenult, i.e., when one or maximally two (light) syllables separated it from the right edge of the word. The constraint *EXTENDED-LAPSE-R, as formalised in Kager (2012), will be considered to account for this behaviour. This constraint will exclude any candidate with a sequence of three or more unstressed syllables occurring between the stressed syllable and the right edge of the word. 
(32) No Extended Lapse

*EXTENDED-LAPSE-R

No more than two unstressed syllables occur between the stress and the right word edge.

In trochaic stress systems, *EXTENDED-LAPSE-R may sanction varying numbers of light syllables occurring between the head foot and the right edge of the word. In cases where the head foot is built on a heavy syllable, up to two light syllables may follow that head foot without incurring any violation of *EXTENDED-LAPSE-R. Nonetheless, when the head foot comprises two light syllables, no more than one light syllable may intervene between that head foot and the right periphery. This observation justifies decomposing the general formulation of *EXTENDED-LAPSE-R into a pair of more specific constraints, each of which maintains the fundamental tenet of *EXTENDED-LAPSE-R, i.e., militating against any final sequence of more than two unstressed syllables.

(33) No Extended Lapse - More Specific Constraints

(a) *EXTENDED-LAPSE $\left(\sigma_{\mu \mu}\right)$-R

No more than two unstressed syllables occur between a stressed heavy syllable and the right word edge.

(b) *EXTENDED-LAPSE $\left(\sigma_{\mu}\right)$-R

No more than two unstressed syllables occur between a stressed hight syllable and the right word edge.

It is essential for SA to utilise *EXTENDED-LAPSE $\left(\sigma_{\mu \mu}\right)$-R rather than $*$ EXTENDED-LAPSE $\left(\sigma_{\mu}\right)$-R to prohibit stress placement on a preantepenultimate $\mathrm{CVC}$, as demonstrated in (34), and to allow it on a preantepenultimate $\mathrm{CV}$, as detailed later in this subsection.

In the grammar of SA, *EXTENDED-LAPSE $\left(\sigma_{\mu \mu}\right)$-R will dominate WSP to rule out initial stress on forms such as *['mak.ta.ba.tih] 'his library'. However, *EXTENDED-LAPSE $\left(\sigma_{\mu \mu}\right)$-R must be ranked lower than WSP-UP $\mu \mu$ to optimise forms where stress assignment extends beyond the final trisyllabic window such as

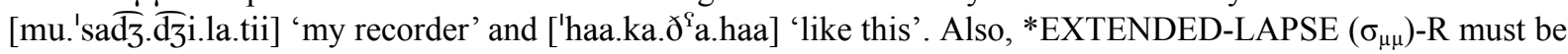
ranked lower than WBYP to allow mora assignment to apply, which consequently produces more harmonic prosodification, even when that would create a sequence of three or more unparsed syllables, even in step 1 when footing has not applied yet. Analysing the stress placement in [mak.'ta.ba.tih] 'his library' shows how *EXTENDED-LAPSE $\left(\sigma_{\mu \mu}\right)$-R forces stress rightward away from the preantepenult. 
(34) HS analysis of stress on leftmost CV syllables (Avoiding Preantepenultimate CVC)

(i) Step 1 of $/$ maktabatih $\rightarrow$ [mak.'ta.ba.tih] 'his library'

\begin{tabular}{|c|c|c|c|c|c|c|c|}
\hline $\begin{array}{cccc}\mu & \mu & \mu & \mu \\
\mid & \mid & \mid & \mid \\
\mathrm{m} \text { a k t } & \text { a b b a t } & \mathrm{i} h\end{array}$ & $\begin{array}{l}z \\
z \\
i \\
\vdots \\
z \\
z\end{array}$ & \begin{tabular}{l}
$\overrightarrow{3}$ \\
\multirow{3}{5}{} \\
1 \\
$\frac{1}{2}$ \\
3
\end{tabular} & 窟 & 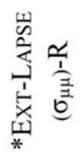 & $\begin{array}{l}\tilde{w} \\
3\end{array}$ & 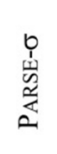 & $\begin{array}{l}\frac{c}{1} \\
\text { 空 } \\
\frac{1}{3} \\
\frac{3}{3}\end{array}$ \\
\hline $\begin{array}{rllll}\text { a. } \rightarrow \quad & \mu \mu & \mu & \mu & \mu \mu \\
& \mid & \mid & \mid & \mid\end{array}$ & & & & & 2 & 4 & \\
\hline 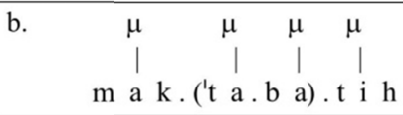 & & & $2 \mathrm{~W}$ & & $\mathrm{~L}$ & $2 \mathrm{~L}$ & $1 \mathrm{~W}$ \\
\hline 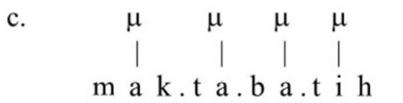 & & & $2 \mathrm{~W}$ & & $\mathrm{~L}$ & 4 & \\
\hline
\end{tabular}

(ii) Step 2 of $/$ maktabatih $/ \rightarrow$ [mak.'ta.ba.tih] 'his library'

\begin{tabular}{|c|c|c|c|c|c|c|c|}
\hline 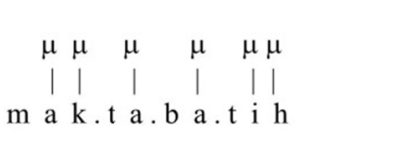 & 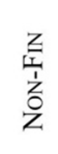 & 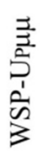 & $\begin{array}{l}\text { ते } \\
\text { है }\end{array}$ & 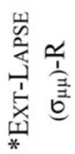 & $\begin{array}{l}n \\
3 \\
3\end{array}$ & 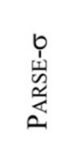 & 秀 \\
\hline 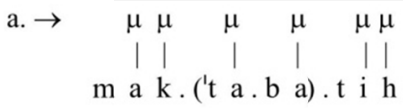 & & & & & 2 & 2 & 1 \\
\hline $\begin{array}{lllll}\text { b. } & \mu \mu & \mu & \mu & \mu \mu \\
\mid & \mid & \mid & || \\
\text { ('m a k).t } & \text { a.b a.t } & \text { i h }\end{array}$ & & & & $1 \mathrm{~W}$ & $1 \mathrm{~L}$ & $3 \mathrm{~W}$ & $3 \mathrm{~W}$ \\
\hline 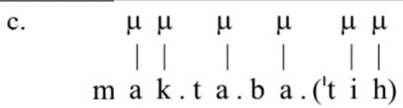 & $1 \mathrm{~W}$ & & & & $1 \mathrm{~L}$ & $3 \mathrm{~W}$ & $\mathrm{~L}$ \\
\hline 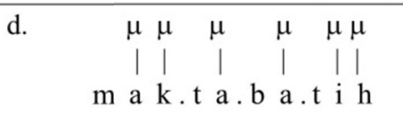 & & & & & 2 & $4 \mathrm{~W}$ & $\mathrm{~L}$ \\
\hline
\end{tabular}

(iii) Step 3 of $/$ maktabatih/ $\rightarrow$ [mak.'ta.ba.tih] 'his library'

\begin{tabular}{|c|c|c|c|c|c|c|c|}
\hline 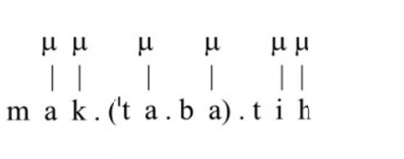 & $\begin{array}{l}z \\
\frac{z}{1} \\
\frac{1}{1} \\
\vdots \\
z\end{array}$ & 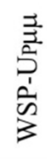 & $\sum_{\substack{i \\
3}}^{0}$ & 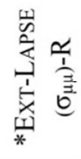 & 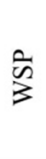 & 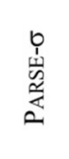 & 竞 \\
\hline 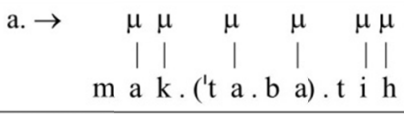 & & & & & 2 & 2 & 1 \\
\hline 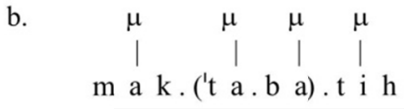 & & & $2 \mathrm{~W}$ & & $\mathrm{~L}$ & 2 & 1 \\
\hline 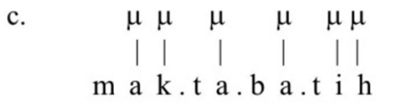 & & & & & 2 & $4 \mathrm{~W}$ & $\mathrm{~L}$ \\
\hline
\end{tabular}

A comparison between candidates (34 ii a and b) shows how *EXT-LAPSE $\left(\sigma_{\mu \mu}\right)$-R tips the balance in favour of the intended winning candidate. Assigning stress to a preantepenultimate heavy syllable, in an attempt to satisfy WSP, will result in a sequence of three unparsed syllables at the right word edge. This configuration will unavoidably violate the higher ranked *EXT-LAPSE $\left(\sigma_{\mu \mu}\right)$-R, and excludes any such candidate. Consequently, it is logical to assume that a CVC penult/antepenult is assigned stress not because it is heavy but primarily because it constitutes the rightmost non-final foot. This argument could also be extended to final CVCC sequences. 
One important issue remains in the analysis of stress on CV syllables. This involves initial stress in quadrisyllabic words. A footing such as ('L.L).L.H will always be assessed as more harmonic than L.L.L.('H) because NON-FIN dominates both WSP and ALIGN-HD-R. Yet, the constraint ranking developed so far is incapable of rejecting a footing such as L.('L.L).H where stress is not assigned to the leftmost light syllable. This false output will be selected as the most harmonic at least because it is a better satisfier of ALIGN-HD-R.

To resolve this issue, it is imperative that the word stress system in SA be treated as an example of the so-called default-to-opposite-edge stress systems. In this language, stress is basically assigned to the rightmost heavy syllable; otherwise, it is assigned to the leftmost light syllable. A constraint that takes the form of ALIGN L ( $\hat{\sigma}_{\mu}$, PrWd) will account for this behaviour, and will rule out any candidate such as L.('L.L).H. The general format of such constraint is introduced in Zoll (1996) arguing that a stressed light syllable be considered as an example of marked structure. Walker (1997) formalises this constraint, and Kager (2007) utilises it for default-to-opposite systems. This constraint is formalised as follows, Walker (1997):

(35) Default-to-opposite-edge

\section{ALIGN L $\left(\hat{\sigma}_{\mu}, \operatorname{PrWd}\right)$}

For all Stressed Light Syllables there exists some Prosodic Word such that the left edge of the Stressed Light Syllable and the left edge of the Prosodic Word are shared.

ALIGN L ( $\sigma_{\mu}$, PrWd) must be ranked higher than ALIGN-HD-R if the footing ('L.L).L.H is to be assessed as more harmonic than L.('L.L).H. On the other hand, PARSE- $\sigma$ must outrank ALIGN L ( $\sigma_{\mu}$, PrWd) to render suboptimal any entirely non-parsed candidate such as H.L.L.L, which vacuously satisfies ALIGN L $\left(\hat{\sigma}_{\mu}, \operatorname{PrWd}\right)$, when compared with the true output H.('L.L).L, which minimally violates ALIGN L ( $\left.{ }_{\mu}, \operatorname{PrWd}\right)$, as the stressed light syllable is non-initial. Analysing the stress assignment in a word such as ['ra.ga.ba.tih] 'his neck' shows ALIGN L $\left(\sigma_{\mu}\right.$, PrWd $)$ in action. 
(36) HS analysis of stress on leftmost CV syllables (Initial Stressed Light Syllable)

(i) Step 1 of /ragabatih/ $\rightarrow$ ['ra.ga.ba.tih] 'his neck'

\begin{tabular}{|c|c|c|c|c|c|c|c|c|}
\hline 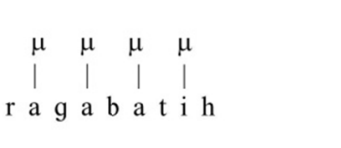 & $\begin{array}{l}z \\
z \\
\frac{z}{1} \\
\vdots \\
0 \\
z\end{array}$ & $\begin{array}{l}3 \\
\frac{3}{3} \\
\frac{1}{3} \\
0 \\
3\end{array}$ & 窟 & 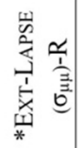 & $\hat{n}_{3}$ & 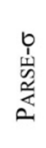 & 光 & $\begin{array}{l}\frac{\alpha}{1} \\
\text { 章 } \\
\frac{3}{3} \\
\frac{3}{4}\end{array}$ \\
\hline 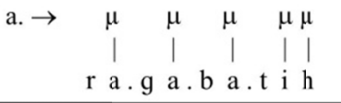 & & & & & 1 & 4 & & \\
\hline 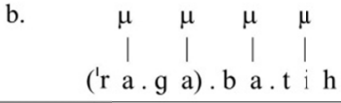 & & & $1 \mathrm{~W}$ & & $\mathrm{~L}$ & $2 \mathrm{~L}$ & & 2 \\
\hline 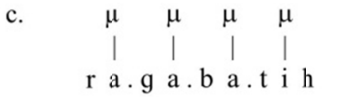 & & & $1 \mathrm{~W}$ & & $\mathrm{~L}$ & 4 & & \\
\hline
\end{tabular}

(ii) Step 2 of /ragabatih/ $\rightarrow$ ['ra.ga.ba.tih] 'his neck'

\begin{tabular}{|c|c|c|c|c|c|c|c|c|}
\hline $\begin{array}{cccc}\mu & \mu & \mu & \mu \mu \\
\mid & \mid & \mid & \mid\end{array}$ & 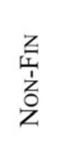 & 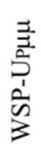 & 產 & 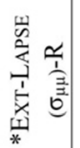 & $\stackrel{\hbar}{\bar{n}}$ & 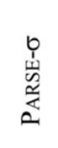 & 莺 & $\begin{array}{l}\frac{2}{1} \\
\text { 党 } \\
\frac{1}{3} \\
\frac{3}{z}\end{array}$ \\
\hline 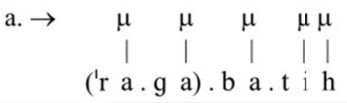 & & & & & 1 & 2 & & 2 \\
\hline 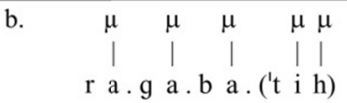 & $1 \mathrm{~W}$ & & & & $\mathrm{~L}$ & $3 \mathrm{~W}$ & & $3 \mathrm{~W}$ \\
\hline 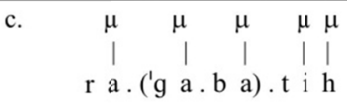 & & & & & 1 & 2 & $1 \mathrm{~W}$ & $1 \mathrm{~L}$ \\
\hline 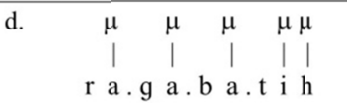 & & & & & 1 & $4 \mathrm{~W}$ & & L \\
\hline
\end{tabular}

(iii) Step 3 of /ragabatih/ $\rightarrow$ ['ra.ga.ba.tih] 'his neck'

\begin{tabular}{|c|c|c|c|c|c|c|c|c|}
\hline 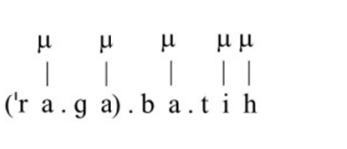 & 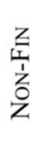 & 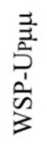 & 产 & 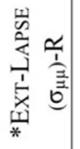 & $\begin{array}{l}\hat{n} \\
\vdots\end{array}$ & 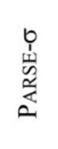 & $\frac{\sqrt{Z}}{\mathrm{z}}$ & 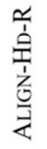 \\
\hline 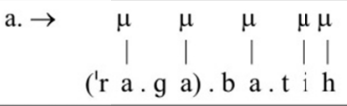 & & & & & 1 & 2 & & 2 \\
\hline b. $\quad \begin{array}{ccccc}\mu & \mu & \mu & \mu \mu \\
& \mid & \mid & \mid & \mid\end{array}$ & & & & & 1 & $4 \mathrm{~W}$ & & $\mathrm{~L}$ \\
\hline
\end{tabular}

The constraint ALIGN L is the reason why (36 ii c) loses the contest with (36 ii a). Failing to align the left edge of the stressed light syllable with that of the prosodic word proved to be detrimental (Note 15).

\subsubsection{Stress on Final CVVC and CVV Syllables}

In this final subsection of the proposed account for SA word stress system, the specific instances of final stress are discussed in detail. All patterns analysed thus far are characterised by non-final stress. Even with word final CVCC sequences, the head foot is not considered to be final, as the final consonant is assumed to form a degenerate syllable occurring between the head foot and the right edge of the word. The constraint that plays the most active role in screening out forms with a final head foot is NON-FIN. To allow stress placement on final CVVC and CVV syllables means allowing some true outputs to violate NON-FIN. Such violation of this relatively high ranked constraint will only be sanctioned under duress. Specifically, stress will be assigned to a final CVVC or CVV syllable when there is no other intrinsically prominent heavy syllable in the form. Before 
spelling out the details of the analysis, it is essential to explain how a final CVVC syllable compares to a final CVV syllable and how it contrasts with a final CVCC sequence.

The justification for adopting the account of a final degenerate syllable in final CVCC sequences is to allow stress placement on the heavy CVC syllable preceding the final degenerate syllable without violating NON-FIN. It is not feasible, however, to implement a similar analysis with final CVVC syllables. Being intrinsically prominent, i.e., having two underlying (upper layer) moras, such syllables may not be prevented from attracting stress away from a non-final CVV/CVG syllable unless they are considered to be final in the prosodic word, and consequently violating NON-FIN. Thus, and drawing on Watson (2002), the assumption is that the final consonant in CVVC syllables is parsed by the final syllable. Nonetheless, that consonant will be nonmoraic, and it will be linked directly to the syllable node because the undominated constraint SYLLBIN rules out any attempt to exceed the bimoraic maximum imposed on syllables.

(37) Final Extrametrical Consonant

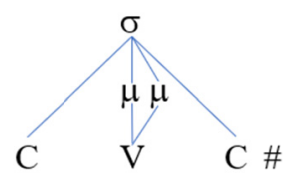

In this regard, it must be noted that the undominated *COMPLEX will necessitate that the final consonant in CVCC syllables be analysed as extrasyllabic, constituting a degenerate syllable, as assigning it to the syllable node will inevitably create a complex margin. On the other hand, assigning the final consonant in a CVVC syllable to the syllable node will not violate *COMPLEX.

Unless the final CVVC syllable constitutes one prosodic unit that is final in the PrWd, NON-FIN may not secure stress placement on a non-final CVV or CVG syllable. When peripherality is interpreted on the basis of the units of the prosodic hierarchy, a foot erected on a final CVVC syllable will violate NON-FIN as no prosodic unit intervenes between it and the right edge of the prosodic word. On the other hand, any foot erected on a non-final CVV or CVG sequence will not be considered final as at least one underlying mora will separate it from the right edge. NON-FIN will not only rule out stress on a final CVV syllable, but it will also ban stress on a final CVVC syllable as no final consonant in this case intervenes between a foot erected on the rhyme of a final CVVC and the right periphery of the prosodic word. Therefore, final CVVC and CVV syllables are treated equally in this regard.

With this understanding of how final CVVC and CVV syllables are distinguished from final CVCC sequences, it is now possible to analyse their behaviour regarding stress assignment, in different environments. The two sets in (38) reveal varying behaviour. In both, all forms end in CVVC/CVV syllables, but these syllables do not always succeed in attracting stress.

\section{(38) Final CVVC/CVV and Stress Placement}

(i) Final Stress

(a) [mak.('tuub)] 'letter'

(b) [jik.tu.('buu)] 'they write' (ii) Non-final Stress

(a) [('s'aa).buun] 'soap'

(b) [?a.('saa).mii] 'names'

What characterises forms in (38 i) is the fact that their final syllables are the only intrinsically prominent heavy syllables in their domain. All other syllable types in that set are either CV, which are not prominent, or CVC, which are not intrinsically prominent (i.e., do not contain two upper layer moras). Conversely, the forms in (38 ii) have other intrinsically prominent syllables in addition to the final ones. Drawing on Watson (2002), the proposed account capitalises on this distinction.

To account for the behaviour outlined in (38), a version of PK-PROM (Prince and Smolensky 1993/2004) is needed to favour feet erected on upper layer moras over ones containing a lower layer mora. Such constraint will dominate NON-FIN to render stress on final CVV acceptable in [jik.tu.'buu] 'they write' but not in [('ka.ta).buu] 'they wrote', where another non-final foot (a better option) is also erectable on upper layer moras. A local conjunction between PK-PROM and WSP is required, however, to ensure that penultimate stress in *[mak.'ta.bih] is ruled out, as detailed later in this subsection. Being a local conjunction, a constraint such as PK-PROM\&WSP is only violated when both specific versions, detailed below, of the two constraints PK-PROM and WSP are violated in a certain candidate. Employing this conjunction will certainly optimise all forms in (38). For example, unless the final CVV syllable in the sequence CVC.CV.CVV is footed and stressed, this conjunction is violated. 
The alternative in such forms is footing the initial CVC syllable and assigning it stress violating both PK-PROM and WSP. By comparing that to forms such as ['ka.ta.buu], it will be clear that there is no need to violate NON-FIN as choosing not to erect a foot on the final CVV and have it built instead on the previous CV.CV sequence will satisfy PK-PROM, and consequently not violate the conjunction. This is true because both possible feet [('ka.ta).buu] and *[ka.ta.('buu)] are erected on upper layer moras. The same rationale is applied to forms with non-final CVV/CVG syllables and final CVVC/CVV syllables, where the non-final intrinsically heavy syllable is always stressed.

As indicated above, the constraint that will be added to the hierarchy and ranked higher than NON-FIN is a local conjunction in the sense of Smolensky (1995). Precisely, it is a local conjunction of Peak Prominence and Weight-to-Stress Principle, where both are defined on the basis of the prominence relation holding between the upper and lower moraic layers.

(39) Local Conjunction (PK-PROM\&WSP)

(a) PK-PROM-UP $\mu \mu$

$\operatorname{Peak}(\mathrm{x})>\operatorname{Peak}(\mathrm{y})$ if $\mathrm{x}=\mathrm{Ft}$ with upper layer moras and $\mathrm{y}=\mathrm{Ft}$ with a lower layer mora.

(b) WSP-UP $\mu \mu$

Heavy syllables with upper layer moras are prominent in foot structure and on the grid.

Before proceeding to the derivations, there are two issues to address. To disfavour the unfooted *[CVC.CV.CVV] candidate which vacuously satisfies both PK-PROM\&WSP and NON-FIN, when competing with the true output [CVC.CV.('CVV)] which violates NON-FIN, a constraint that might be named HARMONIC EXHAUSTIVITY (HAREXHAUS) should be ranked above NON-FIN to exclude any candidate which does not improve in prosodification. This constraint could be formalised as follows:

(40) Harmonic Exhaustivity

\section{HAREXHAUS}

The output has more prosodic structure than the input.

The derivation converges when no further prosodification is possible, i.e., when further prosodification would incur fatal violations.

The other issue concerns faithfulness to input footing. It is vital to assume that footing applied at a previous step is never lost at a following step. This is important to make the derivation converge on a footed form that might violate NON-FIN, rather converge on a form that lost its footing and vacuously satisfies NON-FIN, as both forms may equally violate HAREXHAUS. This constraint is not far-fetched; it is basically the 'strict inheritance' argued for in Pruitt (2010), which ranks undominated in the grammar of SA.

(41) Strict Inheritance

\section{$\operatorname{STRINH}(\mathrm{Ft})$}

Feet are not altered or removed.

The three constraints, PK-PROM\& WSP, HAREXHAUS, and STRINH(Ft), are ranked above NON-FIN to account for the distinction between stressed and unstressed final CVVC and CVV syllables, as shown in the derivations below. 
(42) HS analysis of stress on final CVVC syllables

(i) Step 1 of $/$ maktuub/ $\rightarrow$ [mak.'tuub] 'letter'

\begin{tabular}{|c|c|c|c|c|c|c|c|c|}
\hline $\begin{array}{c}\mu \\
m \text { a } \\
\mid\end{array}$ & 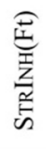 & 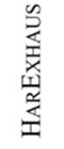 & 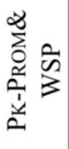 & $\begin{array}{l}z \\
\frac{z}{1} \\
\frac{1}{2} \\
0 \\
z\end{array}$ & 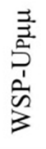 & 產 & 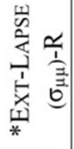 & $\begin{array}{l}\text { के } \\
\hat{\xi}\end{array}$ \\
\hline 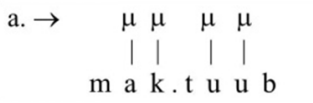 & & & & & 1 & 1 & & 1 \\
\hline 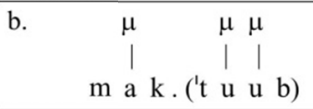 & & & & $1 \mathrm{~W}$ & $\mathrm{~L}$ & $2 \mathrm{~W}$ & & 1 \\
\hline 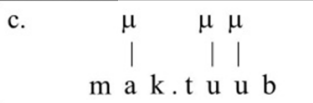 & & $1 \mathrm{~W}$ & & & 1 & $2 \mathrm{~W}$ & & 1 \\
\hline
\end{tabular}

(ii) Step 2 of $/$ maktuub/ $\rightarrow$ [mak.'tuub] 'letter'

\begin{tabular}{|c|c|c|c|c|c|c|c|c|}
\hline $\begin{array}{cccc}\mu & \mu & \mu \\
\mid & \mid & \mid & \mid \\
\mathrm{m} & \mathrm{a} & \mathrm{k} \cdot \mathrm{t} & \mathrm{u} \\
\mathrm{u} & \mathrm{b}\end{array}$ & 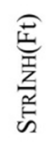 & 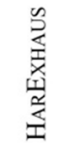 & 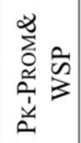 & $\begin{array}{l}z \\
\text { i } \\
\vdots \\
\vdots \\
z\end{array}$ & 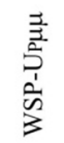 & 產 & 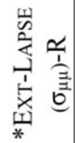 & $\begin{array}{l}\hat{\infty} \\
3\end{array}$ \\
\hline 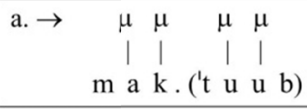 & & & & 1 & & 1 & & 1 \\
\hline 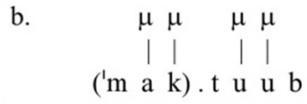 & & & $1 \mathrm{~W}$ & $\mathrm{~L}$ & $1 \mathrm{~W}$ & 1 & & 1 \\
\hline 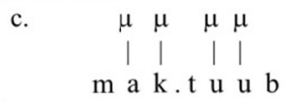 & & $1 \mathrm{~W}$ & & $\mathrm{~L}$ & $1 \mathrm{~W}$ & 1 & & $2 \mathrm{~W}$ \\
\hline 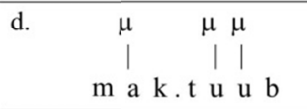 & & $1 \mathrm{~W}$ & & $\mathrm{~L}$ & $1 \mathrm{~W}$ & $2 \mathrm{~W}$ & & $2 \mathrm{~W}$ \\
\hline
\end{tabular}

(iii) Step 3 of /maktuub/ $\rightarrow$ [mak.'tuub] 'letter'

\begin{tabular}{|c|c|c|c|c|c|c|c|c|}
\hline 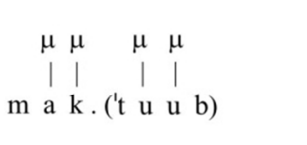 & 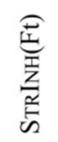 & 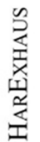 & 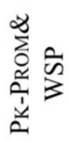 & 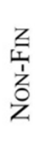 & $\begin{array}{l}\overrightarrow{3} \\
\frac{3}{5} \\
\frac{1}{0} \\
3 \\
3\end{array}$ & $\begin{array}{l}\text { 空 } \\
\text { B. }\end{array}$ & 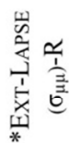 & $\begin{array}{l}\tilde{n} \\
\xi\end{array}$ \\
\hline 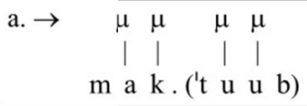 & & 1 & & 1 & & 1 & & 1 \\
\hline 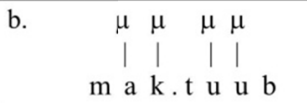 & $1 \mathrm{~W}$ & 1 & & $\mathrm{~L}$ & $1 \mathrm{~W}$ & 1 & & $2 \mathrm{~W}$ \\
\hline
\end{tabular}

In step 2, PK-PROM\&WSP decides the winner, between the two competing candidates (42 ii a and b). The winning candidate [mak.('tuub)] satisfies this constraint as stress is assigned to the prominent peak, the final CVVC syllable. On the other hand, the suboptimal candidate * [('mak).tuub] violates both conjoined constraints PK-PROM-UP $\mu \mu$ and WSP-UP $\mu \mu$, as the final bimoraic and prominent syllable is unstressed. Candidates (42 ii c and d) are disfavoured because they exhibit no improvement in their prosodification, i.e., no footing/stress assignment is applied. In step 3, the two competing candidates tie in their violation of HAREXHAUS as none adds any prosodic structure, but (b) is worse in that regard as it loses the footing in the input, causing a fatal violation of $\operatorname{STRINH}(\mathrm{Ft})$.

The following tableau, step 1 of the derivation, shows how a non-final CVV syllable attracts stress away from a final CVVC syllable. 
(43) Non-final CVV attracting stress away from a final CVVC

Step 1 of $/ \mathrm{s}^{\mathrm{S}}$ aabuun $/ \rightarrow$ ['s'aa.buun] 'soap'

\begin{tabular}{|c|c|c|c|c|c|c|c|c|}
\hline $\begin{array}{c}\mu \mu \quad \mu \mu \\
|||| \mid \\
s^{s} \text { a a b u u n }\end{array}$ & 突 & 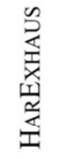 & 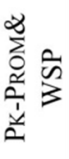 & $\begin{array}{l}z \\
\frac{z}{1} \\
\frac{1}{2} \\
0 \\
z\end{array}$ & $\begin{array}{l}\frac{3}{3} \\
5 \\
5 \\
\frac{1}{5} \\
3\end{array}$ & 產 & 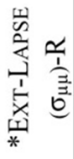 & $\begin{array}{l}\bar{n} \\
\hat{3}\end{array}$ \\
\hline 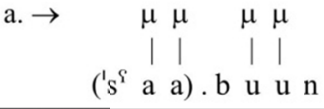 & & & & & 1 & 1 & & 1 \\
\hline b. $\quad \begin{array}{cc}\mu \mu \quad \mu \mu \\
|| \quad|| \\
\text { s }^{s} \mathrm{a} a \cdot(\text { a } \mathrm{u} u \mathrm{u}\end{array}$ & & & & $1 \mathrm{~W}$ & 1 & 1 & & 1 \\
\hline $\begin{array}{ccc}\text { c. } & \mu \mu \quad \mu \mu \\
& \mid \text { | } \quad|| \\
& \text { s }^{s} \text { a a a b u u n }\end{array}$ & & $1 \mathrm{~W}$ & & & $2 \mathrm{~W}$ & 1 & & $2 \mathrm{~W}$ \\
\hline
\end{tabular}

In this case, where the derivation obviously converges in step 2, NON-FIN emerges decisive in the evaluation of candidates (43 a and b). Both candidates satisfy PK-PROM\&\&WSP as stress in each is assigned to a bimoraic prominent syllable. Therefore, there is no pressing need to violate NON-FIN, the reason why (b) is rendered suboptimal (Note 16).

A similar analysis is predicted to achieve the true outputs in forms with final CVV syllables. The derivation in (44) is an example. 
(44) HS analysis of stress on final CVV syllables

(i) Step 1 of /jiktubuu/ $\rightarrow$ [jik.tu.'buu] 'they $m s$. write'

\begin{tabular}{|c|c|c|c|c|c|c|c|c|}
\hline 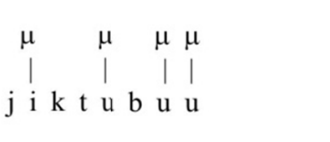 & 㺼 & 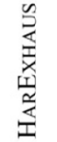 & 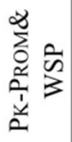 & $\begin{array}{l}z \\
z \\
\dot{L} \\
\vdots \\
\vdots \\
z\end{array}$ & 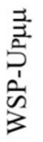 & 產 & 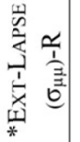 & $\frac{\hat{n}}{\xi}$ \\
\hline 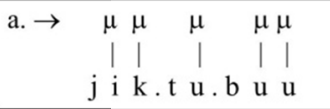 & & & & & 1 & & & 2 \\
\hline 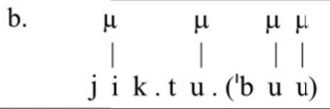 & & & & $1 \mathrm{~W}$ & $\mathrm{~L}$ & $1 \mathrm{~W}$ & & $1 \mathrm{~L}$ \\
\hline 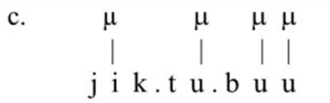 & & $1 \mathrm{~W}$ & & & 1 & $1 \mathrm{~W}$ & & $1 \mathrm{~L}$ \\
\hline
\end{tabular}

(ii) Step 2 of $/$ jiktubuu/ $\rightarrow$ [jik.tu.'buu] 'they $m s$. write'

\begin{tabular}{|c|c|c|c|c|c|c|c|c|}
\hline 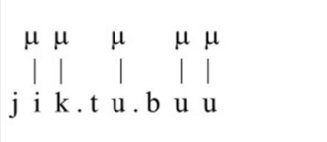 & 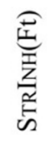 & 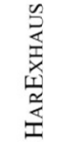 & 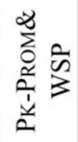 & $\begin{array}{l}z \\
z \\
\frac{z}{1} \\
\vdots \\
z\end{array}$ & 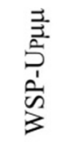 & 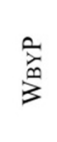 & 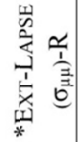 & $\begin{array}{l}\hat{5} \\
3\end{array}$ \\
\hline 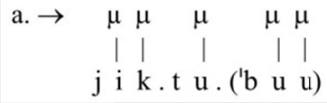 & & & & 1 & & & & 1 \\
\hline 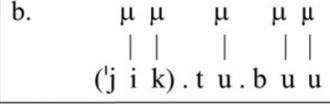 & & & $1 \mathrm{~W}$ & L & $1 \mathrm{~W}$ & & & 1 \\
\hline 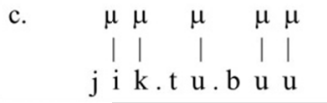 & & $1 \mathrm{~W}$ & & $\mathrm{~L}$ & $1 \mathrm{~W}$ & & & $2 \mathrm{~W}$ \\
\hline 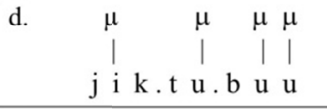 & & $1 \mathrm{~W}$ & & L & $1 \mathrm{~W}$ & $1 \mathrm{~W}$ & & 1 \\
\hline
\end{tabular}

(iii) Step 3 of /jiktubuu/ $\rightarrow$ [jik.tu.'buu] 'they $m s$. write'

\begin{tabular}{|c|c|c|c|c|c|c|c|c|}
\hline $\begin{array}{ccccc}\mu & \mu & \mu & \mu \mu \\
\mid & \mid & \mid & \mid & \mid \\
\mathrm{j} & \mathrm{i} & \mathrm{k} \cdot \mathrm{t} & \mathrm{u} \cdot(\mathrm{l} b \mathrm{u} & \mathrm{u})\end{array}$ & 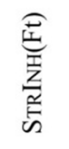 & 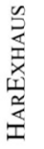 & 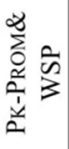 & $\begin{array}{l}z \\
\frac{z}{1} \\
\frac{1}{z} \\
0 \\
z\end{array}$ & $\begin{array}{l}\overrightarrow{3} \\
\overrightarrow{3} \\
5 \\
\frac{1}{n} \\
\frac{1}{3} \\
3\end{array}$ & 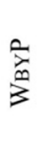 & 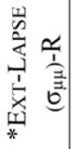 & $\begin{array}{l}\text { के } \\
\vdots\end{array}$ \\
\hline 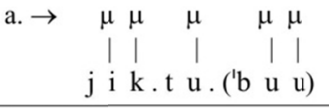 & & 1 & & 1 & & & & 1 \\
\hline 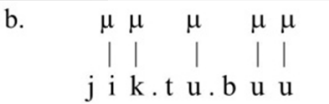 & $1 \mathrm{~W}$ & 1 & & $\mathrm{~L}$ & $1 \mathrm{~W}$ & & & $2 \mathrm{~W}$ \\
\hline
\end{tabular}

Again, candidate (44 ii a) wins in step 2 because it gives priority for footing/stress assignment to the only intrinsically prominent heavy syllable in the word, which happens to be the final CVV syllable. This final stress is contrasted with a case of non-final stress in some forms which also have a final CVV syllable, as demonstrated in (45). 
(45) Initial CVCV sequence attracting stress away from a final CVV

Step 1 of $/ \mathrm{katabuu} / \rightarrow$ ['ka.ta.buu] 'they $m s$. wrote'

\begin{tabular}{|c|c|c|c|c|c|c|c|c|}
\hline $\begin{array}{cccc}\mu & \mu & \mu & \mu \\
\mid & \mid & \mid & \mid \\
k & a & t & a \\
b & u & u\end{array}$ & 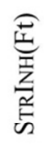 & 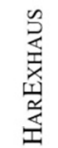 & 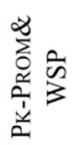 & 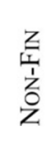 & 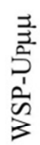 & i & 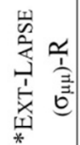 & $\begin{array}{l}\bar{w} \\
\xi\end{array}$ \\
\hline 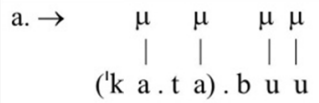 & & & & & 1 & & & 1 \\
\hline 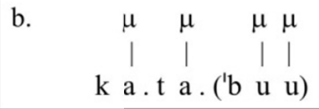 & & & & $1 \mathrm{~W}$ & $\mathrm{~L}$ & & & $\mathrm{~L}$ \\
\hline 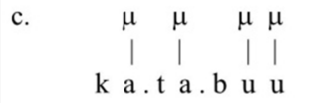 & & $1 \mathrm{~W}$ & & & 1 & & & 1 \\
\hline
\end{tabular}

What is of interest is the fact that stress is assigned to the initial CV syllable rather than the final CVV syllable, basically to avoid a NON-FIN violation. Candidates (a) and (b) in (45) satisfy PK-PROM\&WSP as both assign stress to a syllable with only upper layer moras. This description, obviously, does not apply to candidate (44 ii b).

It is appropriate now to go back to those forms of the template CVC.CV.CVC and examine footing/stress assignment. As mentioned above, Watson (2002) indicated that more research is needed to account for the initial stress placement in words such as ['mak.ta.bih] 'library'. In particular, the two-layered moraic analysis offered in Watson (2002) will falsely assign stress to the penult, which is the head of the only bimoraic sequence that may be footed at the upper moraic layer, as illustrated in (8) above. In the proposed account, assigning stress to the penult will only be possible by allowing a PARSE- $\mu$ violation in a candidate with some footing configuration such as *[mak.('ta.bi)h], which does not obviously represent the true output. Although such footing parses more syllables than the true output [('mak).ta.bih], it incurs a more fatal violation, as demonstrated in (46), which joins the derivation in step 2 after mora assignment has applied.

(46) Non-final CVC attracting stress away from a final CVCVC sequence

(i) Step 2 of /maktabih/ $\rightarrow$ ['mak.ta.bih] 'library'

\begin{tabular}{|c|c|c|c|c|c|c|c|c|}
\hline $\begin{array}{cccc}\mu \mu & \mu \quad \mu \mu \\
\mid & \mid & || \\
\mathrm{mak} \cdot \mathrm{t} & \mathrm{a} \cdot \mathrm{b} & \mathrm{i} h\end{array}$ & 胥 & 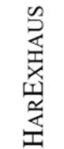 & 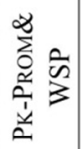 & $\begin{array}{l}z \\
\frac{z}{1} \\
\frac{1}{z} \\
z \\
z\end{array}$ & 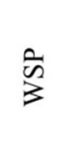 & $\sum_{*}^{0}$ & 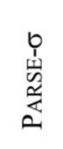 & 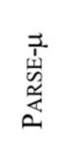 \\
\hline a. $\rightarrow \quad \begin{array}{cccc}\mu & \mu & \mu & \mu \mu \\
\mid & \mid & \mid & \mid\end{array}$ & & & & & 1 & & 2 & \\
\hline b. $\quad \begin{array}{ccc}\mu \mu \quad \mu & \mu \mu \\
\mid & \mid\end{array}$ & & & & & 1 & $1 \mathrm{~W}$ & $1 \mathrm{~L}$ & $1 \mathrm{~W}$ \\
\hline c. $\quad \begin{array}{ccc}\mu \mu \quad \mu \quad \mu \mu \\
|| \\
\text { m a k.t a }\left({ }^{\prime} b \quad h\right)\end{array}$ & & & & $1 \mathrm{~W}$ & 1 & & 2 & \\
\hline $\begin{array}{llll}\text { d. } \quad & \mu \mu \quad \mu \quad \mu \mu \\
|| & \mid & \mid \text { | } \\
& \text { m a k.t a.b i h }\end{array}$ & & $1 \mathrm{~W}$ & & & $2 \mathrm{~W}$ & & $3 \mathrm{~W}$ & \\
\hline 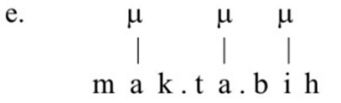 & & $1 \mathrm{~W}$ & & & L & & $3 \mathrm{~W}$ & \\
\hline
\end{tabular}

None of the two main competing candidates (46 a and b) violates PK-PROM\&WSP, as both vacuously satisfy WSP-UP $\mu \mu$. What makes (b) less harmonic is the *NONCD $\left(\mathrm{C}_{\mu}\right)$ violation that resulted from the needless non-parsing of the final mora, which had been assigned in step 1 earlier to satisfy WBYP.

A final note is about forms such as [('da.ra).sat] 'she learnt' analysed in (30) above. As explained in (31 ii), allowing final mora non-parsing will produce the false output *[da.('ra.sa)t] that satisfies WSP but violates 
* $\operatorname{NONCD}\left(\mathrm{C}_{\mu}\right)$. On the contrary, the true output [('da.ra).sat] satisfies * $\operatorname{NONCD}\left(\mathrm{C}_{\mu}\right)$ but violates WSP. The two violations cancel one another as these two constraints have the same ranking. The false output *[da.('ra.sa).t] will be ruled out, nonetheless, by both constraints ALIGN L and PARSE- $\mu$, which are satisfied in the true output.

By this, the proposed account of SA word stress system is concluded. The constraint hierarchy in (47) includes all the constraints employed in the analysis:

(47) Constraint Hierarchy for SA Word Stress

FTBIN, RHTYPE=T, HEADMAX, MONOHEADEDNESS, SYLLBIN, STRINH(Ft) $>>$

HAREXHAUS, PK-PROM\&WSP $>>$

NON-FIN $>$ WSP-UP $\mu \mu>$ WBYP $>>$ *EXT-LAPSE $\left(\sigma_{\mu \mu}\right)-\mathrm{R}>>$ WSP, $* \operatorname{NONCD}\left(\mathrm{C}_{\mu}\right)>>$ PARSE- $\sigma>>$ ALIGN L, PARSE- $\mu>>$ ALIGN-HD-R

\section{Conclusion}

The gradual prosodification model proposed to analyse the word stress system in SA accounts for the attested distinction between non-final CVV and CVG syllables and other syllable types. The two different paths of prosodification meant that a derivation could begin with footing/stress assignment immediately, and whenever underlying moraicity allows it, or it could start with mora assignment followed by footing/stress assignment. Only forms with a non-final CVV/CVG syllable would take the former, i.e., the shorter path. All other patterns need the full range of prosodic operation leading to the ultimate stress assignment.

The only case where final stress is exceptionally sanctioned in SA is accounted for with the help of a local conjunction between two metrical constraints. In SA, stress on a word-final syllable (or foot) is allowed when a final CVV or CVVC syllable represents the only sequence available for footing on the upper moraic layer. To optimise such stress placement, the constraint PK-PROM\&WSP is ranked higher than NON-FIN to rule out any possible competitor with a non-final foot erected on a CVC syllable, which will always violate both conjoined constraints. On the other hand, NON-FIN will help reject final stress in any form where non-final footing/stress assignment satisfies PK-PROM\&WSP.

\section{References}

Al-Mohanna, F. (2010). Positional syllable maximality: Syllabification in Hejazi. Journal of King Saud University - Languages and Translation, 22, 47-67.

Aoun, J. (1979). Is the syllable or the supersyllable a constituent? In K. Safir (Ed.), Papers on Syllable Structure, Metrical Structure, and Harmony Processes. MIT Working Papers in Linguistics, 1, 140-148.

Bakovic, E. (1996). Foot harmony and quantitative adjustments. MS, Rutgers University. (ROA-168).

Broselow, E. (1992). Parametric variation in Arabic dialect phonology. In E. Broselow, M. Eid \& J. McCarthy (Eds.), Perspectives on Arabic Linguistics IV (pp. 7-45). Amsterdam, NL: John Benjamins. https://doi.org/10.1075/cilt.85.04bro

Broselow, E., Chen, S., \& Huffman, M. (1997). Syllable weight: Convergence of phonology and phonetics. Phonology, 14, 47-82. https://doi.org/10.1017/S095267579700331X

Crowhurst, M. (1996). An optimal alternative to Conflation. Phonology, 13, 409-424. https://doi.org/10.1017/S0952675700002694

Davis, S. (2011). Geminates. In O. Marc van et al. (Eds.), The Blackwell Companion to Phonology II (pp. 873-897). Malden, MA and Oxford, UK: Wiley-Blackwell. https://doi.org/10.1002/9781444335262.wbctp0037

Davis, S., \& Ragheb, M. (2014). Geminate representation in Arabic. In S. Farwaneh \& H. Ouali (Eds.), Perspectives on Arabic Linguistics XXIV-XXV (pp. 3-20). Amsterdam, NL: John Benjamins. https://doi.org/10.1075/sal.1.04dav

Halle, M., \& Vergnaud, J. (1987). An Essay on Stress. Cambridge, MA: MIT Press.

Hayes, B. (1981). A metrical theory of stress rules. Doctoral dissertation (1980), MIT. Distributed by the IULC, 1981. New York: Garland Press, 1985.

Hayes, B. (1989). Compensatory lengthening in moraic phonology. Linguistic Inquiry, 20, 253-306.

Hayes, B. (1995). Metrical Stress Theory: Principles and case studies. Chicago, IL: University of Chicago Press.

Hulst, H. van der, \& Hellmuth, S. (2010). Word accent systems in the Middle East. In H. Harry van der et al. 
(Eds.), A Survey of Word Accentual Patterns in the Languages of the World (pp. 615-646). Berlin, DE and New York, NY: De Gruyter Mouton. https://doi.org/10.1515/9783110198966.1.615

Hyde, B. (2002). A restrictive theory of metrical stress. Phonology, 19, 313-359. https://doi.org/10.1017/S0952675703004391

Kager, R. (1999). Optimality Theory. Cambridge, UK: Cambridge University Press. https://doi.org/10.1017/CBO9780511812408

Kager, R (2007). Feet and metrical stress. In L. Paul de (Ed.), The Cambridge Handbook of Phonology (pp. 519-536). Cambridge, UK: Cambridge University Press.

Kager, R. (2012). Stress in windows: Language typology and factorial typology. Lingua, 122, 1454-1493. https://doi.org/10.1016/j.lingua.2012.06.005

McCarthy, J. (2000). Harmonic serialism and parallelism. In M. Hirotani (Ed.), Proceedings of the North East Linguistics Society 30 (pp. 501-524). Amherst, MA: GLSA Publications.

McCarthy, J. (2002). A Thematic Guide to Optimality Theory. Cambridge, UK: Cambridge University Press. https://doi.org/10.1017/CBO9780511613333

McCarthy, J. (2006). Restraint of analysis. In E. Bakovic, J. Ito \& J. McCarthy (Eds.), Wondering at the Natural Fecundity of Things: Essays in Honor of Alan Prince (pp. 195-219). Linguistics Research Center, UC Santa Cruz.

McCarthy, J. (2010a). An introduction to Harmonic Serialism. Language and Linguistics Compass, 4, 1001-1018. https://doi.org/10.1111/j.1749-818X.2010.00240.x

McCarthy, J. (2010b). Harmonic Serialism Supplement to Doing Optimality Theory. MS, University of Massachusetts, Amherst. (ROA-1099).

McCarthy, J. (2016). The theory and practice of Harmonic Serialism. In J. McCarthy \& J. Pater (Eds.), Harmonic Grammar and Harmonic Serialism (pp. 47-87). London, UK: Equinox Publishing Ltd.

McCarthy, J., \& Prince, A. (1990). Prosodic morphology and templatic morphology. In M. Eid \& J. McCarthy (Eds.), Perspectives on Arabic Linguistics II: Papers from the Second Annual Symposium on Arabic Linguistics (pp. 1-54). Amsterdam: John Benjamins. https://doi.org/10.1075/cilt.72.05mcc

McCarthy, J., \& Prince, A. (1993a). Generalized Alignment. In Yearbook of Morphology (pp. 79-153). Dordrecht: Kluwer. https://doi.org/10.1007/978-94-017-3712-8_4

McCarthy, J., \& Prince, A. (1993b). Prosodic Morphology: Constraint interaction and satisfaction. Technical Report. Rutgers University Center for Cognitive Science, New Brunswick, NJ.

Morén, B. (2000). The puzzle of Kashmiri stress: Implications for weight theory. Phonology, 17, 365-396. https://doi.org/10.1017/S0952675701003967

Ola, O. (1995). Optimality in Benue-Congo Prosodic Phonology and Morphology. Doctoral dissertation, University of British Columbia, BC.

Prince, A. (2002). Arguing optimality. In A. Carpenter, A. Coetzee \& P. de Lacy (Eds.), University of Massachusetts Occasional Papers in Linguistics 26: Papers in Optimality Theory II (pp. 269-304). Amherst, MA: GLSA.

Prince, A., \& Smolensky, P. (1993, 2004). Optimality Theory: Constraint interaction in generative grammar. Malden, MA, \& Oxford: Blackwell. Revision of 1993 technical report, Rutgers University Center for Cognitive Science.

Pruitt, K. (2008). Iterative foot optimization and locality in stress systems. MS, University of Massachusetts, Amherst, MA. (ROA-999).

Pruitt, K. (2010). Serialism and locality in constraint-based metrical parsing. Phonology, 27, 481-526. https://doi.org/10.1017/S0952675710000229

Pruitt, K. (2012). Stress in Harmonic Serialism. Doctoral dissertation, University of Massachusetts, Amherst, MA.

Rosenthall, S., \& Harry van der, H. (1999). Weight-by-position by position. Natural Language and Linguistic Theory, 17, 499-540. https://doi.org/10.1023/A:1006283229291

Ryan, K. (2019). Prosodic Weight: Categories and continua. Oxford, UK: Oxford University Press. 
https://doi.org/10.1093/oso/9780198817949.001.0001

Ryan, K. (2020). VV > VC > V for stress: Coercion vs. prominence. Linguistic Inquiry, 51(1), 124-140. https://doi.org/10.1162/ling_a_00325

Selkirk, E. (1981). Epenthesis and degenerate syllables in Cairene Arabic. MIT Working Papers in Linguistics, 3, 209-232.

Selkirk, E. (1995). The prosodic structure of function words. In J. Beckman, L. Dickey \& S. Urbanczyk (Eds.), University of Massachusetts Occasional Papers in Linguistics 18: Papers in Optimality Theory (pp. 439-469). Amherst: GLSA.

Sherer, T. (1994). Prosodic phonotactics. Doctoral dissertation, University of Massachusetts, Amherst.

Smolensky, P. (1995). On the internal structure of the constraint component of UG. MS, University of California, Los Angeles. (ROA-86).

Walker, R. (1997). Mongolian stress, licensing and factorial typology. MS, (ROA-172).

Watson, J. (2002). The Phonology and Morphology of Arabic. Oxford, UK: Oxford University Press.

Watson, J. (2009). San'ani Arabic. In K. Versteegh et al. (Eds.), Encyclopedia on Arabic Language and Linguistics IV (pp. 103-106). Leiden, NL: Brill.

Watson, J. (2011). Word stress in Arabic. In O. Marc van et al. (Eds.), The Blackwell Companion to Phonology V (pp. 2990-3018). Malden, MA and Oxford, UK: Wiley-Blackwell. https://doi.org/10.1002/9781444335262.wbctp0124

Wiltshire, C. (2006). Pulaar's stress system: A challenge for theories of weight typology. In J. Mugane et al. (Eds.), Selected Proceedings of the 35th Annual Conference on African Linguistics (pp. 181-192). Somerville, MA: Cascadilla Proceedings Project.

Zoll, C. (1996). Parsing below the segment in a constraint-based framework. Doctoral dissertation, University of British Columbia, BC.

\section{Notes}

Note 1 . Watson $(2002,2011)$ categorically indicated that stress placement may fluctuate in connected speech. Hence, these rules are only generalised for citation forms (i.e., ones produced in isolation).

Note 2. In Hulst and Hellmuth (2010), referring to (Watson p.c.), it is noted that contemporary speakers may also place stress on the penultimate syllable in such words.

Note 3. Other constraints, relatively leading to the same effect, are introduced in the literature. As formalised in Broselow, Chen and Huffman (1997), MORAICCODA requires that "all coda consonants must be dominated by a mora."

Note 4. It should be noted that stressless feet are assumed in some metrical analyses, for example Hyde (2002).

Note 5 . When a certain input triggers the prosodification path in (17b), mora assignment may be allowed to apply after footing/stress assignment has already applied. Although this mora assignment has no bearing on the final outcome regarding stress assignment, it will be assessed as achieving a more harmonic prosodification of an input.

Note 6. The assumption that HEADMAX and MONOHEADEDNESS are undominated rules out the possibility for any secondary stresses. It is worth mentioning though that Watson (2002) talks about fluctuating cases of secondary stresses in SA.

Note 7. The form in (18) will be reanalysed in the next subsection where the constraint ranking is reconsidered.

Note 8. In comparative tableaux, Prince (2002), the arrow shows the most harmonious candidate, and the integers represent the number of violations. All violations of suboptimal candidates are categorised as favouring the winner $(\mathrm{W})$ or favouring the losing candidate being assessed (L).

Note 9. It is worth investigating the question of whether WSP-UP $\mu \mu$ should be universally ranked higher than WSP.

Note 10. Ranking the constraint WSP-UP $\mu \mu$ higher than WBYP and WSP opens the door for a P-OT analysis of SA word stress system. With such ranking, it is possible to give precedence to the intrinsically prominent CVV and CVG syllables, no matter what other syllabic configuration there might be. The underlyingly bimoraic status 
of these syllables will guarantee stress assignment whether or not the two unfaithful prosodic operations are applied in parallel. In this regard, it is worth mentioning that previous P-OT accounts have been proposed. Rosenthall and Hulst (1999) and Morén (2000), for example, assume an approach to complex weight distinctions known as coercion, where the constraint ranking WSP $>$ WBYP dictates that a coda consonant be assigned a mora only when the syllable in which it occurs is assigned stress and when no CVV syllables are present. To achieve the same goal, Wiltshire (2006) and Ryan (2020) propose individual constraints to account for the complex weight distinctions by favouring CVV syllables as more prominent than CVC syllables.

Note 11. The analysis must assume a constraint that militates against footing syllables that dominate non-moraic coda consonants. This is vital to rule out any premorification footing of CVC sequences with adjacent CV or CVC sequences. This constraint might be a coda-specified extension of WBYP or of EXHAUSTIVITY, as formalised in Selkirk (1995).

Note 12. The tableaux in (25) demonstrate how the two constraints WSP-UP $\mu \mu$ and WSP apply in evaluating candidates. Any candidate containing an unfooted, and eventually unstressed, syllable with upper layer moras $(\mathrm{CVV} / \mathrm{CVG})$ will violate both constraints. On the other hand, an unstressed CVC syllable with a lower layer mora assigned to its coda consonant only violates WSP.

Note 13. Allowing PARSE- $\mu$ violation will open the door for a footing configuration such as [CVC.(CV.CV)C] which certainly includes more parsed syllables. Such footing will falsely result in assigning stress to a light penult rather that a heavy antepenult. This issue will be discussed in more detail in the following subsection about stress on final CVVC and CVV syllables.

Note 14. To limit unparsed segments to the final consonant only, the proposed account assumes two undominated constraints. First, instances of medial, rather than final, unparsed segments are ruled out by the Contiguity Constraint, proposed in McCarthy and Prince (1990), which maintains contiguous strings of subsyllabic elements. Secondly, the constraint PARSENUC- $\mu$ (Ola, 1995) guarantees parsing all nuclear moras into syllables.

Note 15. The SA data presented in Watson (2002) included no forms with sequences of more than four CV syllables. A question must be raised regarding how stress may be assigned in SA renderings of Modern Standard Arabic forms such as /raqabatuhu/ 'his neck'.

Note 16. As for words with the template CV.CV.CVVC, which are not clearly exemplified in Watson (2002), the proposed account predicts initial stress [('CV.CV).CVVC]. This prediction remains to be verified by considering more data.

\section{Copyrights}

Copyright for this article is retained by the author, with first publication rights granted to the journal.

This is an open-access article distributed under the terms and conditions of the Creative Commons Attribution license (http://creativecommons.org/licenses/by/4.0/). 